\title{
The Focal 1905 Point of Second Scientific Revolution: An Efficacious Matching of the Pivotal Research Traditions of Classical Physics
}

\section{Nugayev RM*}

Volga Region State Academy, Russian Federation

*Corresponding author: Rinat M Nugayev, Volga Region State Academy, Kazan 33, Universiade Village, The Republic of Tatarstan, The Russian Federation, Tel: +79518968538; Email: rinatnugaev@mail.ru

\section{Research Article \\ Volume 3 Issue 1}

Received Date: December 11, 2019

Published Date: January 16, 2020

DOI: $10.23880 /$ phij-16000132

\section{Abstract}

Einstein's 1905 'annus mirabilis' constituted the focal point of the second scientific revolution. To comprehend in what subtle ways Einstein's medley 1905 works hang together one has to pay special tribute to his strive for unity evinced in the stubborn attempts to coordinate the profound research traditions of classical physics. Though Einstein's adamant efforts sprung out of Max Planck's pioneering attempts to understand electromagnetic phenomena through the lense of conceptual structures of thermodynamics and statistical mechanics. Einstein's light quanta and special relativity turn out to be only pencil sketches of a more mature and oil painting, mere milestones of implementation of maxwellian electrodynamics and statistical thermodynamics efficacious reconcilement research programme. The conception of luminiferous ether was a significant snag for Einstein's statistical thermodynamics in which the pivotal role was played by the light quanta paper. Herewith Einstein was fully aware that his light quanta hypothesis was too audacious to be taken literally. Hence he posited the 'electrodynamics of moving bodies' in a markedly Machian, phenomenological way and the basic relativity postulate was proposed as originating from 'instinctive knowledge'. Though in his criticism of the mouldy research traditions of classical physics Einstein was obviously influenced by David Hume and Ernst Mach, when related to creative momenta, his 1905 reconcilement modus operandi was initiated by Mach's pre-eminent principle of economy of thought but taken in the context of Stevin-Mach 'instinctive knowledge' doctrine and with promising inclinations of regulative spirit of Kantian and Duhem's epistemologies.

Keywords: Scientific revolution; Annus mirabilis; Einstein; Light quanta; Special relativity; Planck; Stevinus; Instinctive knowledge; Mach; Economy of thought; Duhem; Kant; Regulative principles

\section{Introduction}

It is commonly held that Albert Einstein's manifold scientific writings were strongly motivated by the Ideal of Unity of physical laws (see, for instance, van Dongen 2010 and references cited therein) [1]. For instance, in 1949 conspicuous Schilpp collective volume Einstein, famously summing up his achievements, openly admitted that "the special aim which I have constantly kept before me is logical unification in the field of physics" [2]. Respectively, 


\section{Philosophy International Journal}

the scientific career of Einstein after 1915, i.e. after the general relativity had been contrived, was incessant search for unitary theories: Cartan-Weyl geometrical 'Theory of Everything', Kaluza inspired five-dimensional amalgamation of gravitation and electrodynamics, and so on. And it goes without saying that the intrepid Quest for Unity of Nature is best represented precisely by these pre-eminent attempts of Einstein towards unitary theories during almost forty years than by the early writings. However, in my view, Einstein's mature unification accounts and especially his sophisticated general theory of relativity (GRT) arose out of his early writings and first and foremost out of his 1905 dizzy attempts to create special relativity, as well as out of his audacious 1905 light quanta hypothesis. For example, as Einstein recalled later [3], his perseverant efforts to set up the basic GRT tenet - the principle of equivalence - were necessarily drawn upon his quite recent experience of contriving the SRT (special relativity theory).

Likewise, his breakthrough 1905 masterpiece on light quanta commences with highlighting "a profound formal difference between the theoretical conceptions physicists have formed about gases and other ponderable bodies and Maxwell's theory of electromagnetic processes in so-called empty space" [4] (p.86, my italics). The paper ultimately aims at reconcilement of the profound research traditions of classical physics such as classical mechanics and maxwellian electrodynamics. Nay more, Einstein's 1905d special relativity paper also famously starts with unfolding a "deep asymmetry" [5] (p.140) in the common description of electromagnetic induction.

Nevertheless, Einstein definitely was not the first in noticing the cross-contradiction between the primary paradigms of classical physics. At the end of the XIX-th century, three profound classical research traditions were to interact consequentially in Max Planck's striking theory of quanta: thermodynamics, electromagnetic theory and statistical mechanics [6]. Ere 1900, he has made conspicuous contributions to all three but their weight condescended in his creativity from thermodynamics through Maxwell's electromagnetic theory to Boltzmann's statistical approach. Thermodynamics was his never-to be- forgotten 'first love' and an unsallied paragon of scientific achievement. Planck's advances in it were generally recognized before he turned, not without doubts, to much disputed domain of electrodynamics. Statistical mechanics cleaved into Planck's research later and against even more resistance. One of the first pure theoreticians in physics, a recognized leader of German school, Max Planck was particularly sensitive to the intertheoretic context of the basic problems of physics at the turn of the century. He clearly comprehended an origin of the foundational problems lying in the deep lingering conflict between mechanics, statistics, electrodynamics and thermodynamics.

"Nowadays, (the following) two significant fields are set against each other: mechanics and electrodynamics, or, as they are sometimes called, the physics of matter and the physics of ether. The first includes acoustics, heat and chemical processes; the second includes magnetism, optics and radiant heat. Is this subdivision final? I do not think so, mostly because neither of these fields of investigation is divided by strict and firm lines. For instance, does radiant heat belong to mechanics or to electrodynamics? Or to which field must the law of electron movement be attributed? At first sight one can state that it should be attributed to electrodynamics since ponderable matter plays no role for electrons. Let us direct our attention on the movement of electrons in metals. Studying Lorentz's works one can arrive at a conclusion that the laws of such motions are more appropriate for kinetic theory of gases than to electrodynamics" [7] (p.616); (see also Planck's 1906 epochmaking lectures on theory of heat) [8].

Hence the overall aim of the present paper is to take the next step that comes naturally and to reveal the abiding influence of the above mentioned reconcilement on Planck's 1898-1900 Startling writing and especially Einsten's 19021905 writings on SRT genesis and advancement. Respectively, the second part of this paper deals with the circle of reconciliation problems that irrepressibly brought Einstein to the peculiar domain of 'electrodynamics of moving bodies'. Correspondingly, the third part aims at answering the question: what was the train of thought that engendered Einstein to contrive light quanta and SRT on the basis of Planck's promising investigations. It is contended that the former and the latter turn out to be only milestones of implementation of maxwellian electrodynamics, statistical mechanics and thermodynamics productive reconciliation programme that originated in Planck's pioneering efforts. The pivotal role in the programme was played by Einstein's 1905a light quanta paper, since it was definitely the ether conception that put insurmountable obstacles in realization of Einstein's statistical-thermodynamics design. Einstein was fully aware that his light quanta hypothesis was audacious and that he needed to be especially cautious; hence he posited his 'electrodynamics of moving bodies' in a markedly Machian, phenomenological way. In particular, Einstein posited his basic relativity postulate as originating from 'instinctive knowledge'. Hence finally, my ultimate aim will be to exhibit that the pivotal concept necessary to conceive Einstein's 1905 writings as a whole, as well as the subtle order of their arrangement is pre-eminent Mach's principle of Economy of Thought yet taken in the context of the Stevinus-Mach 'instinctive knowledge' doctrine and with some budding inclinations of Kantian epistemology presuming the coincidence of both constructing theory 


\section{Philosophy International Journal}

and integrating intuition of Principle, as well as Duhem's conventionalism.

\section{Einstein, Poincaré, Hume and Mach}

In Germany in the second half of the XIXth century Maxwell's vehement efforts to concord the research programmes of Young-Fresnél, Faraday and Ampére-Weber [9] were reinforced by Hermann Helmholtz. In Helmholtz's conspicuous paradigm charges and currents were considered as the sources of electrical and magnetic fields. Eventually it led to H.A. Lorentz's dualistic worldview of the field equations and the equations of motion exhibited in his 1892-1900 writings. Not by chance Lorentz's theory was an artful fusion of Maxwell's field theory and Wilhelm Weber's particle theory of pre-Maxwellian electrodynamics.

And it was young Albert Einstein who dared to pick the problem up after such boffins as Maxwell, Helmholtz and Lorentz. In 10 August 1899 'Paradies' hotel letter an ETH (Eidgenossiche Technische Hochschule) student informs his fiancée that

"I am more and more convinced that the electrodynamics of moving bodies, as presented today, is not correct, and that it should be possible to present it in a simpler way. The introduction of the term 'ether' into the theories of electricity led to the notion of a medium of whose motion one can speak without being able, I believe, to associate a physical meaning with this statement. I think that the electric forces can be directly defined only for empty space[...] Electrodynamics would then be the theory of the motion of moving electricities and magnetisms in free space: which of the two conceptions must be chosen will have to be revealed by radiation experiments" (Doc. № 52, p.131) [10].

From the very start of his dizzying scientific career Einstein had repeatedly expressed serious doubts on the role of 'des Namens Aether' in classical electrodynamics. Yet his skepticism was selectively directed at Hertz's concept of the ether as a medium with a certain state of motion, but not at the ether concept itself. It was because Einstein attributed major significance to the concept of 'elektrische Massen' and took electric currents as real motions of such charges in empty space, not as the 'Verschwinden elektrische Polarisation in der Zeit'. At the beginning of Einstein's scientific career his Weltanschauung was based on the fine lectures on electricity of his ETH physics teacher prof. H.F. Weber, as it is unfolded by Einstein's lecture notes (see Doc. № 37 and the related comments in Einstein 1987, pp. 223-225) [11].

The 'substantive' concept of electricity was worked out by Wilhelm Weber and was widely implemented by many German-speaking physicists, including H.F. Weber. Therein, at least initially Einstein's common views on electrical masses moving in the immobile ether were quite similar to the dualistic paradigm of H.A. Lorentz. Respectively, Einstein concluded the above mentioned letter recapitulating that 'Strahlungversuche' was needed for choosing between the two standpoints he outlined. And his next, 10 September 1899 'Paradise' letter to Marić displayed a sober idea for experimentally ascertaining the influence of motion relative to the ether on the propagation of light in transparent bodies.

Nevertheless, Einstein's professor of physics expressed no enthusiasm for his work, and Albert made no further mention in his papers and correspondence of his setting force the electrodynamics of moving bodies for almost two years. Nay, 'die prinzipielle Trennung von Lichtaether und Materie', 'Definition absoluter Ruhe', and so on of course were among the topics he strenuously discussed with his close friend Michele Besso (see Einstein's 4 April 1901 letter to Marić). In March 1901 Einstein confidentially informed Mileva that he looked forward to the perfection of "unsere Arbeit uber die Relativbewegung". In September 1901 he proudly informed his close friend Marcel Grossman on working up a simpler method for the investigation of the motion of matter relative to ether, based 'auf gewonlichen Interferenzversuchen'. By December 1901 he was 'arbeite eifrigst' on "die Elektrodynamik bewegter Körper", that promised to become "eine kapitale Abhandlung" (Einstein's 17 December 1901 letter to Marić). A sad calculation mistake had earlier led him to doubt the correctness of his 'Ideen über die Relativbewegung', but he now believed in these ideas even more.

He elicited the motley stuff to prof. Kleiner and the latter even "thought that the experimental method proposed by me is the simplest and most appropriate and conceivable. I was very pleased with the success. I shall certainly write the paper in the coming weeks" (Einstein's letter to Marić, 19 December 1901, p. 189). Despite of prof. Kleiner's sage encouragement and Einstein's strong enthusiasm, no publication on this subject ensued for over three years - till 21 June 1905. Why? - Einstein was really engaged in working on a "capital treatise" on the electrodynamics of moving bodies at the end of 1901. Then he had stopped doing it and retraced to the manuscript only in 1905. What happened in that time, and why had Einstein, being initially a moderate supporter of the ether, became its committed enemy?

To provide a judicious explanation one has first to recall Einstein's derogative evaluation of his youth writings - 'my worthless beginner papers' [12]. The evidence at hand highlights that the planned "kapitale Abhandlung" was a 'far cry' from the $1905 \mathrm{~d}$ thrilling STR paper. On the contrary, now one definitely knows [13] that Einstein arrived at the body of startling results of his 1905 d relativity paper, in a 


\section{Philosophy International Journal}

'sudden burst of creativity' and only after he had perfected his first three works in the spring of 1905. The key insight - the discovery of the relativity of simultaneity - occurred to Einstein only in late May 1905 only after the completion of the 1905c [14] Brownian motion paper. For example, when asked by the biographer Carl Seelig, Einstein elucidated:

"Between the conception of the idea of the special theory of relativity and the completion of the corresponding published paper there passed five or six weeks" [15].

Was it possible that Einstein had relinquished the ether concept on finding out some immaculate, irrefutable physical argument in the works of those luminaries of science whose influence he readily and publicly admitted? This weighty argument could turn out a final straw for growing aversion to rusty metaphysical remnant of the obsolete classical research tradition.

First of all, how significant was Poincaré and Mach's pre-eminent influence? - For instance, in a letter to Michele Besso on 6 March 1952 Einstein recalled:

"These readings [relating to special relativity] were of considerable influence on my development - along with Poincaré and Mach" (Doc. 182) [16].

And how weighty appeared Poincaré's 'Relativity Principle', that maintained relativity of time and space? Already in 1902 Henri Poincaré indicated that

"There is no absolute time. To say two durations are equal is an assertion which has by itself no meaning and which can acquire one only by convention. Not only have we no direct intuition of the equality of two durations, but we have not even direct intuition of the simultaneity of two events occurring in different places: this I have explained in an article entitled ' $\mathrm{La}$ mesure du temps' " (p. 114) [17].

Besides, a droll 'Academia Olympia' member - Einstein's close friend Maurice Solovine - characterized Henri Poincaré's eminent book "La science et l'hypothese" (first published in 1902) as one

"that profoundly impressed us and kept us breathless for many weeks" (p. 6) [18].

However, the relativity principle, immaculately moulded by Henri Poincaré, did not debar the latter to believe in luminiferous ether as in the medium necessary for propagation of electromagnetic waves [19].

As for Ernst Mach's hold, in a letter of 8 April 1952 to Carl Seelig, Einstein openly confessed:

"My attention was drawn to Ernst Mach's 'Science of Mechanics' by my friend Besso while a student, around the year 1897.The book exerted a deep and persisting impression upon me owing to its physical orientation toward fundamental concepts and fundamental laws" (p.636) [20].

The harsh influence of Mach's critique of Newton's rusty concepts of absolute space and absolute time on young Einstein is a humdrum [21,22]. Yet, there is obviously no direct and definite way from abstract philosophical critique of Newtonian mechanics to peculiar postulates of special relativity. In my judgement, the most convincing argument against the common inductivist explanation of the STR genesis consists in the following fact. Let us recall the socalled 'emission theories of light' that contested the lightsconstancy postulate and exchanged it with common Galilean law (that simply added the velocities of light and of its source). These theories [23] had no problems in comprehending the results of the Michelson-Morley experiment since they were specially concocted to explain it away. And they did. But they should not, if the inductivists were right. Thus, Einstein carefully and diligently perused Mach's "Science of Mechanics" already in 1897; yet it did not baffle him to believe in luminiferous ether up to 1905.

Or maybe it was stupendous David Hume? For example, in a letter to Michele Besso in 1948 Einstein once more recalled that

"How far [Mach's writings] influenced my own work is, to be honest, not clear to me. In so far as I can be aware, the immediate influence of D.Hume on me was great. I read him with Konrad Habicht and Solovine in Bern (p. 153) [16].

Yet it should be punctuated that Hume's and Einstein's conceptions of space and time differ substantially [24]. In Hume's lofty epistemological doctrine, space and time are direct abstractions from simple perceptions. On the other hand, Einstein incessantly maintained that the pivotal concepts of science are free creations of the human mind (see, for example, Schilpp's 1949 eminent volume and the references cited therein).

\section{What was the Heavy Train of Thought that Brought Einstein to Light Quanta \& Special Relativity?}

To provide a weighty answer one has to dip first into the STR paper itself [5]. The paper famously starts with revealing a "deep asymmetry" in theoretical reproduction of the phenomena of 'electromagnetic induction'. Experience asserts that the induction current engendered in the conductor by the motion of the magnet depends only on their relative motion. However the Maxwell-Lorentz theory renders two substantially different accounts of the effect that mysteriously lead to one and the same quantitative result. 


\section{Philosophy International Journal}

Yet Albert Einstein was by no means the first to discern profound asymmetries in theoretical representation of the induction phenomenon. In 1885 the asymmetries were indicated by Oliver Heaviside, in 1894 - by Herman Föppl, and in 1898 - by Wielhelm Wien (p.377) [19]. And the thrilling question is not how Einstein became aware of the asymmetries, but what made them so intolerable to him. Einstein followed Hertz, Heaviside, Wien et al. in recognition that "something was rotten in the state" of the MaxwellLorentz theory. Yet he had to render a rather manifold 'diagnosis' and to propose a very peculiar 'cure'.

In my judgement, the key to answer the above question lies in other works of Albert Einstein and first of all in his thrilling 1905 papers. It is a platitude that Einstein published nothing on the topic of optics and electrodynamics of moving bodies prior to 1905. More importantly, it was Albert Einstein himself who had just unfolded another asymmetry - and of more substantial kind - in startling 1905a paper "On an heuristical point of view concerning the processes of emission and transformation of light". The paper was published in the same journal "Annalen der Physik" but three months before the relativity paper. Look at the outset of his 1905a ground-t breaking work:

"There exists a profound formal difference between the theoretical conceptions physicists have formed about gases and other ponderable bodies and Maxwell's theory of electromagnetic processes in so-called empty space" (p.86) [4].

Nevertheless, to comprehend how Einstein arrived at the cross-contradiction between mechanics and electrodynamics one has to precipitate himself to Max Planck's stupendous work first.

It was already pointed out that at the end of the XIXth century, three profound classical research traditions had interacted strongly in Max Planck's oeuvre: thermodynamics, electromagnetic theory and statistical mechanics. Note that for him the role of electrodynamics and statistical mechanics initially was purely instrumental. Maxwell's startling equations and Boltzmann's subtle technique provided merely conceptual tools to solve the problem of irreversibility first and then to grapple with the blackbody radiation.

It should be emphasized that even 'classical theory of black-body radiation' before Planck's vehement efforts did not exist at all. What did really exist was a pile of phenomenological and half-empirical laws provided either at the expense of direct generalization of empirical data or either due to physically meaningless and methodologically too ad hoc assumptions inserted into the body of common scientific knowledge.
To begin with, in 1879 Josef Stefan, as a kind of uncomplicated extrapolation from preliminary experiments, exhibited that the dependence of the black-body radiation density u upon temperature $\mathrm{T}$ is described by the equation $\mathrm{u}=$ $\sigma \mathrm{T}^{4}$. Then S.P. Langley, W. Michelson, H. Weber and F Paschen had obtained expressions for black-body distribution function $\mathrm{u}(v, \mathrm{~T})$, derived from experiments, until $\mathrm{W}$. Wien tried to get the expression for $\mathrm{u}(v, \mathrm{~T})$ from theoretical considerations though in a rather speculative way. For Wien in 1896 a heated gas served as the source of blackbody radiation. In the wake of Vlad Michelson, Wilhelm Wien disclosed that ,in the gas, number of molecules with velocities in the range between $\mathrm{v}$ and $\mathrm{v}+\mathrm{dv}$ is, by Maxwell's distribution law, proportional

to $v^{2} \exp \left(-v^{2} / \alpha^{2}\right)$ with $\alpha$ proportional to the gas temperature $\mathrm{T}$. If we make a rather dubious surmise that the frequency and the intensity of the radiation from a given molecule are both functions only of that molecule's velocity, then the distribution of radiation must obey the equation $\mathrm{u}(v, \mathrm{~T})$ $=\mathrm{F}(\mathrm{v}) \exp (-\mathrm{f}(\mathrm{v}) / \mathrm{T})$. On finding $\mathrm{F}$ and $\mathrm{f}$, Wien obtained an expression (in modern notation, using more exact values for the constants)

$$
u(v, T)=8 \pi h v^{3} / c^{3} \exp (h v / k T)
$$

As a genuinely theoretical product, Wien's distribution law had little significance until Planck rederived it in 1899 in a remarkably different way. His efforts condescended a dubiously -obtained empirical dependence up to a sublime genuinely theoretical law, whose domain of validity was

limited by the inequality $\mathrm{h} / \mathrm{kT}>>1$. Hence Planck's writings represented practically the first effort to construct a true theory of black-body radiation, i.e. they constituted a bold attempt to rederive the radiation density $u(v, T)$ from the 'first principles' of thermodynamics and electrodynamics as opposed to phenomenological efforts to 'guess' the correct expression through experimental data. It is no wonder that Planck met with many obstacles on this thorny path, perseverantly deriving partial theoretical laws, comparing them with experimental results, correcting the laws and checking the results, and so on.

It is well-known that Planck was a theoretician 'par excellence' with thermodynamics taken as a paragon of mature scientific theory. Already in Planck's times thermodynamics became an established and respectable research tradition with a multitude of practical applications. Yet when he arrived at a conclusion that thermodynamics is insufficient, he applied Maxwellian electrodynamics - young and controversial at his times, whose proper empirical verification had just commenced. Nevertheless, Planck, in his quest for comprehension of irreversibility, had to advance his theoretical scheme at the expense of inserting subtle abstract objects into it. And thus he invented resistanceless ideal vibrating resonators- tiny oscillating currents 


\section{Philosophy International Journal}

governed by Maxwell's equations. Planck's ideal constructs had nothing to do with real experimental devices. They had nothing to do with real molecules, atoms or even electrons being rather peculiar theoretical contraptions conjured up to establish thermodynamical equilibrium between matter and radiation.

In 1897 Planck had published the first paper of a fivelpart series entitled “On Irreversible Radiation Processes" [25]. In all the five papers [25-29], as well as in the basic article, which recapitulated their results for the "Annalen der Physik" $[30,31]$, he had scrutinized the attributes of an ideal model consisting of a system of resonators intensively interacting with an electromagnetic field. However, after he had read his first paper to the Academy, a critique by Ludwig Boltzmann was presented to the same audience. Boltzmann contended that, though Planck's complex formulas for resonator absorption and emission were perfect, the reductionist 'irreversibility' programme for which they were designed should necessarily fail. Both Maxwell's equations and the boundary conditions on their solution are surely invariant under time reversal.

When the using of Maxwell's equations turned out to be insufficient, Planck had to implement statistics quite unwillingly, step by step, and under the growing pressure of hard experimental results. The following story is of significant importance here [32,33]. Planck, who intended to broaden the domain of validity of statistical thermodynamics, advanced (via classical continuous notions) thermodynamics of electromagnetic radiation and tried to introduce the entropy of radiation by analogy with its energy. Being a partisan of eminent Ludwig Boltzmann, Max Planck informed the luminary, a father of statistical mechanics about the research, and even presented one of his papers to Boltzmann's judgement. Nevertheless, Boltzmann harshly retorted that Planck would never be able to create a correct theory of statistical thermodynamics of electromagnetic field without inserting previously unknown element of discontinuity into processes of radiation.

Already in 1872, 28 years before Planck's 1900b paper, Boltzmann in his "Furtherinvestigations of thermalequilibrium between gas molecules" pioneered in applying the notions of discrete energy to the exchange processes. Scrutinising the second law of thermodynamics from a statistical point of view, Boltzmann arrived at the notion of 'energy atoms' transpiring themselves in the intricate processes of molecular interactions. The notion of the finite energy amounts that can be exchanged for colliding molecules led Boltzmann to complicated calculations of the number of collisions with the help of combinatorials technique. Nevertheless, due to the prevailing Weltanschauung, Boltzmann took the notions of energy quanta just as an auxiliary mathematical tricks.
Nevertheless, the 'Boltzmann heritage' was rather controversial and very debatable. At first Planck strived to get through by using an electromagnetic analogue of Boltzmann's H-theorem, and when it definitely failed, he had to appeal to the probability calculus and the combinatorial definition of entropy which he hated with all his heart [6].

However, fortunately we have direct evidence of Planck's experiences yet after the events. In a letter to Robert Wood he contended that "Boltzmann explained the existence of thermodynamical equilibrium throughstatistical equilibrium; if his considerations are applied to equilibrium between matter and radiation, one arrives at the conclusion that the transformation of all the energy into radiation [demanded by classical physics] can be avoided by the supposition that energy should exist from the very beginning in some discrete portions" [6] (p.79). Planck later recalled that through all his life, either in publications or correspondence, Boltzmann was coldly stressed with him. Only in his last years, when Planck informed him about the atomistic justification of his thrilling radiation law, Boltzmann changed his attitude radically and became exceedingly friendly to Planck.

By the beginning of 1900, only single facet of Boltzmann's treatment of irreversibility was still absent from Planck's successful research programme, the application of combinatorials, and by the end of the year, Planck had accumulated it, too. Though what forced him to do so was no longer the intricate problem of irreversibility. On the contrary, it was the passionate search for a radiation law that could like a house on fire pass the test of new, more subtle tests.

The apparent weakness of the derivation of the Wien distribution law, that Planck submitted to the "Annalen der Physik" in November 1899, was the lack of a uniqueness proof for the function he had boldly defined as oscillator entropy. Pointing on their measurements of the frequency distribution of radiation from a new piece of experimental apparatus, the first laboratory black cavity, Lummer and Pringsheim contrived a new formula for the blackbody radiation that significantly deviated from Wien's law. But Planck had happily eliminated the difficulty in a paper submitted for publication in February 1900, in which he asserted to have derived, rather than defined, oscillator entropy for the first time, supporting Wien's law again.

Yet the experiment turned out to be stubborn. In a paper, reported to the Physics Section of the Naturforscherversammlung on the 18 September 1900, Lummer and Pringsheim maintained that the Wien-Planck distribution law did not represent their perseverant measurements on black radiation in the low frequency region. In this range, achieved only with the aid of recently 


\section{Philosophy International Journal}

developed techniques, the discrepancies between experiment and theory were near $50 \%$ and blatantly could not be due to simple experimental errors.

The evidence was truly convincing, yet Planck was prepared to meet it now. In a paper presented to the Physical Society on 19 October 1900 he referred to the proof of the Wien law he had submitted to the "Annalen der Physik" in March, and at once underscored its shortcoming. The entropy of $\mathrm{n}$ oscillators must, he contended, depend not simply on their total energy, as was supposed, but on the energy $U$ of a single oscillator. The expression $\delta^{2} S / \delta^{2} U=-\alpha / U$ discovered earlier is too rough and should be exchanged for a more subtle equation. Planck had proposed an expression that "is the simplest by far of all the expressions which yield S as a logarithmic function of $U$ (a condition which probability theory suggests) and which besides coincides with the Wien law for small values of $U$ ". If the equation for $S$ is taken as the first term $(-\mathrm{U} / \alpha)$ in a power series expansion of expression

$\left(\delta^{2} S / \delta^{2} U\right)^{-1}$ his new form follows directly by the addition of a term proportional to $U^{2}$.

With the expression $\delta^{2} S / \delta^{2} U=-\alpha / U(U+\beta)$, two integrations, the standard condition $\delta S / \delta U=1 / T$ an application of the displacement law provides a new distribution law $U=b v / \exp (\alpha v / T)-1$. This radiation formula, Planck proudly stated, "so far as I can see by quick inspection, represents the hitherto published observational data just as satisfactorily as the best previously proposed distribution function...I therefore feel justified in directing attention to this new formula, which, from the standpoint of electromagnetic radiation theory, I take to be the simplest excepting Wien's".

New refined measurements quickly demonstrated the last equation to be superior to all the other distribution laws. However Planck had to disclose the route to the formula that was less ad hoc. "On the exact day", Planck says, "when I first formulated this law, I began to devote myself to the task of investing it with a real physical meaning, and that issue led me of itself to the consideration of the relationship between entropy and probability, and thus to Boltzmann's line of thought" [7]. As Thomas Kuhn shrewdly punctuated, those remarks have commonly been understood as recording Planck's ponderous conversion from phenomenological thermodynamics to a statistical one. But that breakthrough had occurred at least a year, and more probably three years, before. When Planck referred to "the relation between entropy and probability", he did not have in mind the statistical approach in general but only, as his words openly suggested, Boltzmann's fascinating combinatorial definition of entropy. Planck, who must have elicited the combinatorial definition in Boltzmann's stupendous "Gas Theory", appears to have been the first scholar to acknowledge even its existence.

Yet Planck's initial derivation of the Wien law contained an important internal contradiction. The $\mathrm{n}$ resonators he surveyed were required to be independent, but his argument depended on supposing that their total energy Un was distributed equally among them. An improved argument would uncover the various ways in which that energy might be divided between resonators just as Boltzmann, in his combinatorial studies, had divided the total energy of a gas among its molecules. Expression for Planck's distribution law $U=b v / \exp (\alpha v / T)-1$ can be dexterously manipulated to yield $1 / \mathrm{T}$ as a function of $\mathrm{U}$ and $v$, and $1 / \mathrm{T}$ is just $\delta S / \delta U$. After integration we get

$$
S=(b / a) \log \left\{(1+U / b v)^{1+U / b v} /(U / b v)^{U / b v}\right\}+\text { const }
$$

Planck should have been encouraged by its clear resemblance to Boltzmann's epoch-making expression for the logarithmic relation between entropy and probability. Alack, the equation applies only to a single resonator with energy $U$ in equilibrium with a radiation field and is not suitable for correct interpretation in probabilistic terms.

Thus let one contemplate $\mathrm{N}$ independent resonators of frequency $v$ set up in equilibrium with their radiation field. Their total entropy should be equal to NS, while their total energy should be equal to NU. If combinatorials are to be introduced, the total energy must be subdivided into $\mathrm{P}$ elements of size $\varepsilon$, so that $\mathrm{P} \varepsilon=\mathrm{NU}$. Multiplying Planck's equation for $\mathrm{S}$ by $\mathrm{N}$ and substituting $\mathrm{P} \varepsilon / \mathrm{N}$ for $\mathrm{U}$ yields

$$
S N=(b / a) \log \left\{(N+P \varepsilon / b v)^{N+P \varepsilon / b v} / N^{N}(P \varepsilon / b v)^{P \varepsilon / b v}\right\}+c o n s t
$$

To provide an expression involving only integers, the size of the energy element $\varepsilon$ must be set equal to bv. The quantity in \{\} then reduces, for large $\mathrm{N}$ and $\mathrm{P}$, to $(\mathrm{N}+\mathrm{P}-1)$ ! / $(\mathrm{N}-1)$ ! $\mathrm{P}$ ! But that thrilling formulae is the common expression for the number of ways in which $\mathrm{P}$ indistinguishable elements can be distributed over $\mathrm{N}$ distinguishable boxes. Thus the first stages in Planck's application of Boltzmann's relation between entropy and probability were completed. But the profound problem still remained. The combinatorial expression found by working backwards from Planck's distribution law decidedly differed from the one Boltzmann had advanced in deriving the equilibrium distribution of gas molecules. Hence Planck had to exhibit that it is proportional to the probability appropriate to equilibrium radiation. Planck's ultimate problem was to derive the expression for the entropy of a particular distribution of the total energy 


\section{Philosophy International Journal}

E over $\mathrm{N}$ resonators. Then he had to find its maximum with respect to variation of the distribution of the total energy over frequency. To compute the entropy of an arbitrary distribution Planck was forced to use combinatorial and hence he followed Boltzmann in subdividing the energy continuum into the elements of finite size.

"We must now give the distribution of energy over the separate resonators of each group, first of all the distribution of the energy $\mathrm{E}$ over the $\mathrm{N}$ resonators of frequency $\mathrm{v}$. If $\mathrm{E}$ is considered to be a continuously divisible quantity, this distribution is possible in infinite many ways. We consider, however, - this is the most essential point in the whole calculation, $-\mathrm{E}$ to be composed of a very definite number of equal parts and use there the constant of nature $h=6,55 \mathrm{x}$ 10-27 (erg x sec). This constant multiplied by the frequency, $v$, of the resonator yields the energy element $\varepsilon$ in ergs, and, dividing $E$ by $\varepsilon$, one obtains the number, $\mathrm{P}$, of energy elements to be distributed over the N resonators" (p.83) [31].

Then Planck defines a 'complexion' (an expression, he punctuates, "used by Boltzmann for a similar concept") as a particular specification of the set of numbers, which fixes the number of elements $\varepsilon$ attributed to the various resonators in the set of $\mathrm{N}$. The total number of possible complexions is $\mathrm{R}$. To determine the equilibrium distribution one is forced to maximise $\mathrm{R}$ or $\log \mathrm{R}$ by varying the energies at the various frequencies. Straightforward manipulations exhibit that the entropy $(\log R)$ will have a maximum if $U_{v}=h v / \exp (h v / k T)$ -1 . The corresponding expression for the distribution of the

field is $u_{v}=\left(8 \pi v^{2} / c^{3}\right) \mathrm{U}_{v}$.

Note that both in his original derivation papers and far more clearly, in his famous «Lectures» (1906), Plancks radiation theory is incompatible with the real quantization of the resonator energy. His theory only timorously requires fixing the size of the small intervals into which the energy continuum is subdivided for purposes of combinatorial computation. In Planck's peculiar theory resonator emission and absorption are still governed by Maxwell's equations. Planck did repeatedly use expressions like UN $=$ Phv. But UN is the total energy of $\mathrm{N}$ resonators. Restricting it to integral multiples of $\mathrm{h} v$ does not impose any similar restriction on the energy of an individual resonator, which may vary continuously.

Thus, though Planck constantly appealed to the reliable experimental results, the role of the experiment in constructing his theory should not be overestimated. Blackbody experiments played the role of the important factor, that only forced Planck to apply statistics in the growing rates. In the lack of experimental data Planck would not use Boltzmann's combinatorials in full rate: he did not like them whole-heartedly. The use of combinatorials was necessarily connected with introducing such distinctive and dubious hypotheses that Planck, an admirer of classical thermodynamics, vehemently tried to avoid.

One cannot maintain that Planck's epoch-making distribution law was a direct generalization of experimental results. On the contrary, Planck's route to it was 'from top to bottom'. Surely, he had to take the experimental evidence into account; yet it forced him not to 'deduce from phenomena' but to apply more theory instead. As one of the first pure theoreticians in physics, a leader of German theoretical physics, Planck can in no ways be characterized as a 'bungler' lucky to discover a law whose value he was not able to understand on his own. As a professional theoretician, Planck was very sensitive to the importance of the problem he tried to solve and to the necessity of treating it in the intertheoretic context. He clearly comprehended an origin of the problem lying in the profound contradictions between mechanics, statistics, electrodynamics and thermodynamics [7] (p. 616). See also Planck's fascinating 1906 "Lectures on Heat Radiation", [8] (p.105).

Note that it was the fact of the origin of early quantum theory arising out of the clash between classical electrodynamics and statistical mechanics that was punctuated by a Russian theorist of the XX-th century beginning:

"But the most curious thing is that the quantum idea should be engendered half a century ago, when the kinetic theory of the matter was created. This idea is intimately connected with molecular structure of matter and is a specific reflection of this structure".

Planck clearly understood that the introduction of $\varepsilon$ $=h v$ sprung out of the gap between statistical mechanics and electrodynamics. Eventually true elimination of the cross-contradiction resulted in the invention of quantum electrodynamics, in construction of quantum theory of radiation that took electromagnetic particles as Boltzmann's molecules that can gain energy under collisions with usual molecules and resonators. An important scholar to notice it appeared to be Albert Einstein.

In the first part of the 1905a paper Einstein excavated that the joint application of mechanical and electrodynamic "theoretical pictures" for scrutinizing the black-body radiation leads not only to the blatant contradictions with experiments (his paper did not even cite Lummer \& Pringsheim or Rubens \& Curlbaum impeccable results), but to the staggering paradox that cannot be circumvented by common means. To exhibit it, Einstein dexterously contrives the gedankenexperiment with the both theories. 


\section{Philosophy International Journal}

He contemplates an imaginary cavity containing free electromagnetic field, gas molecules and Planck's resonators and arrives at a strong statement that the joint application of mechanics and electrodynamics unavoidably leads to Rayleigh-Jeans law for energy density of the black-body radiation. Nevertheless, "this relation which we found as the condition for dynamic equilibrium does not only lack agreement with experiment, but it also shows that in our picture there can be no question of a definite distribution of energy between aether and matter", since "the greater we choose the range of frequencies of resonators, the greater becomes the radiation energy in space and in the limit we get

$$
\int_{0}^{\infty} \rho_{V} \mathrm{~d} v=(R / N)\left(8 \pi / L^{3}\right) T \int_{0}^{\infty} v^{2} \rho_{\mathrm{V}} \mathrm{d} v=\infty
$$

(Here $\mathrm{R}$ denotes the universal gas constant, $\mathrm{N}$ the number of 'real molecules' in one gram-equivalent, $\mathrm{T}$ the absolute temperature, $\mathrm{L}$ the velocity of light, $v$ the frequency, and $\rho_{v} \mathrm{~d} v$ the energy per unit volume of that part of the radiation whose frequency lies between $v$ and $v+\mathrm{d} v$ ). Although it is commonly believed that in the 1905a light quanta paper Einstein was concerned with an explanation of the photoelectric effect, the tentative study of the epochmaking masterpiece exhibits that this was not the case. The measurements of the effect at that time were not sufficiently accurate to point definitely to a violation of classical behavior [34]. Einstein was bothered not so much by the evidence relating to photoeffect and appealed to fluorescence, photoelectricity and photoionization data only as to indirect evidence in favor of his model. On the opposite, Einstein had mostly grappled with the contemplation of the profound contradiction between mechanics and electrodynamics, as well as with the efficacious ways out of it.

So, what was a sober reason of Einstein's deep interest to the contradictions between the mature classical physical theories? It is no wonder that to find a judicious answer one has to delve into Einstein's 1946 'Autobiographical Notes' once more since namely this source represents the most extensive and systematic recital of evolution of Einstein's views made by Einstein himself:

"It was Ernst Mach who, in his History of Mechanics, shook this dogmatic faith [in classical mechanics]; this book excercised a profound influence upon me in this regard while I was a student. I see Mach's greatness in his incorruptible skepticism and independence; in my younger years, however, Mach's epistemological position also influenced me greatly..." (p. 21) [2].

Note that Mach's "Science of Mechanics" is teeming with stubborn attacks against classical mechanics dominating role in physics (pp. 495, 517) [21]. On Mach's strong shoulders, Einstein could therefore freely juxtapose Newtonian mechanics, Maxwellian electrodynamics and statistical thermodynamics without reducing one to the others. Yet the top-notch element of Machian epistemology that persistently accompanied Einstein all his life was Mach's preeminent Principle of Economy of Thought: "All science aims to replace experience with the shortest possible intellectual operations". That is why science felicitously condenses an infinity of facts into a single law, and why it forms an extremely concentrated fusion of a multitude of laws in what it calls a theory.

"It is a matter of arranging in systematic order the facts presented that have to be reconstructed by thought to form a system out of them so that each fact may be recovered and reestablished with the least intellectual expence" [35].

Thereafter, in a review of the STR genesis, published in "Science" in 1940, Einstein maintains that "the theory of relativity arose out of efforts to improve, with reference to logical economy, the foundation of physics as it existed at the turn of the century" [36] (p. 329); [37] (p.277); and [38] (p. 23).

And a proper explanation of Einstein's reasons for writing his 1905a paper and its connections with the other 1905 ones can be discovered in his "Autobiographical Notes" again. Due to Einstein, the first stage of "the revolution begun by the introduction of the field" [2] (p. 37) consisted in the contrivance and the advancement of the Maxwellian electrodynamics. All the pre-maxwellian studies of physical interactions (the theories of Newton, Ampére, Weber, Riemann et al.) were accounts of interactions between several material points. Thanks to Faraday and Maxwell, the Electromagnetic Field was inserted into the texture of the XIX-th century physics as an element of physical reality having equal rights with the Material Point. The problem situation was characterized by fatal "dualism which lies in the fact that the material point in Newton's sense and the field as continuum are used as elementary concepts side by side. Kinetic energy and field-energy appear as essentially different things" (ibid, p.37; my italics).

It is important that, as an inevitable consequence of the dualism, a "fundamental crisis set in, the seriousness of which was suddenly recognized due to Max Planck's investigations into heat radiation (1900).The history of this event is all the more remarkable because, at least in its first phase, it was not in any way influenced by any surprising discoveries of an experimental nature"( ibid, p.37; my italics).

Max Planck's thrilling way of reasoning $(\varepsilon=h v)$ obviously contradicted the mechanical and electrodynamical basis upon which his derivation depended. Note that according 
to Einstein himself "My own interest in those years was less concerned with the detailed consequences of Planck's results, however important these might be. My major interest was: What general conclusions can be drawn from the radiation formula ... concerning the structure of radiation and even more concerning the electro-magnetic foundations of physics?" [2] (p. 47).

Thus Einstein's attraction in the 1905a paper to the subject of theory of quanta was provoked by its reconciliation possibilities, for its capacities to arrive at a successful fusion of Maxwellian electrodynamics and Boltzmann's statistical thermodynamics. Herewith Einstein was fully aware that his quantum hypothesis was too bold to be taken literally. Next we will demonstrate that he definitely did not maintain: "light quanta of energy $\varepsilon=h v$ exist". His formulation was more cautious: it would be possible to expose monochromatic radiation in certain limits as if it were composed of mutually independent energy quanta.

I reckon that to comprehend Einstein's true attitude to light quanta in the context of its unification capacities one should start from the following quotation from Jeroen van Dongen's bona fide, assiduous book "Einstein's Unification":

"On a number of occasions Einstein actually expressed himself quite appreciative of Kant's ideas, and some aspects of Einstein's thought did rather resemble the Kantian philosophy. Both for instance emphasized the virtue of striving for unity in science" [1] (p. 49).

And, in my view, for main conspicuous milestones of Einstein's 1905 creativity Kant's influence should be taken as crucial. Firstly, the very possibility of Kant's significant influence on young Einstein is apparent: Kantian philosophy was dominant among the educated classes in Germany in the late XIX-th century, and the extent to which it was taught in German high school was 'overwhelming'[39]. Respectively, neo-Kantianism (Neukantianismus with its laconic motto: "Zurück to Kant!") was the prevalent philosophical movement in German high school from the 1870's until the First World War. It is no wonder that Einstein first read Kant at the age of thirteen and again at the age of sixteen [40] (p. 49). Thereafter, being an Eidgenössiche Technische Hochshule (ETH) student in Zurich, he had a lucky opportunity to continue his Studium von Kant, Kant's superlative Nachlaß in the winter semester of 1897 at the lecture course on the "Theory of Scientific Thought" of Dr. August Stadler, a distinguished neo-Kantian of Marburg school [10] (pp. 4550). Dr. August Stadler was Herman Cohen's first doctoral student at Marburg, and Einstein elected to enroll also in Stadler's general course on Kant.

Later the degree of his acquaintance with the works of Kant only increased. For example, in 1918 Einstein confidentially reported to Max Born:

"I am reading Kant's Prolegomena here, among other things, and am beginning to comprehend the enormous suggestive power that emanated from the fellow and still does".

In his 1936 profound "Physik und Realität" he contended that "One may say 'the eternal mystery of the world is its comprehensibility'. It is one of the greatest realizations of Immanuel Kant that the postulation of a real external world would be senseless without this comprehensibility" [41] (p. 292).

Likewise, in 1949, famously reflecting on the basic principles of reasoning in theoretical physics, Einstein avowed that "the theoretical attitude here advocated is distinct from that of Kant only by the fact that we do not conceive of the categories as unalterable...They appear to be a priori only insofar as thinking without the positing of the categories and of concepts in general would be as impossible as breathing in the vacuum" [2] (p. 674).

Yet what could attract 1905 Einstein in murky waters of Kantian epistemology?

According to Kant it is our freedom from the world that makes science possible. The sensible world conforms to certain basic laws because the human mind artfully constructs it according to certain laws. Constructivist foundation for scientific knowledge implies that a priori knowledge of ' things in themselves' is impossible. Yet in the Appendix to the "Dialectic" of the first Critique Kant strived to provide a faint rehabilitation of the ideas of traditional metaphysics (Wolff, Locke) by contending that the ideas of reason play a significant role in the conduct of natural science if they are understood regulatively, i.e. if they are considered to represent not metaphysical beings or entities, but rather ultimate goals and directions of scientific enquiry.

In the "Critique of Pure Reason" Kant sedulously divided the human intellect into the independent faculties of sensibility, understanding and reason. Respectively, the principles governing these faculties belong either to constitutive principles, or to regulative ones. The constitutive principles were considered as strict rules for the construction of the phenomenal world (e.g. Newton's laws, Maxwell's equations, etc.). Thus, distinction between the constitutive and regulative principles appears to be drawn in Kant's masterpiece along the following lines: the constitutive principles are those that govern the function of understanding and are necessary conditions of experience, whereas regulative principles - the 'ideas of reason' - govern the function of reason and are not instantiated in experience in the same way. Later none other than Hans Reichenbach took constitutive principles as synthetic a priori ones and 


\section{Philosophy International Journal}

maintained that to retain a role for such principles they should be relativized and understood as a priori only from the perspective of a particular mature theory like Newtonian mechanics or Maxwellian electrodynamics.

Though constitutive principles are necessary conditions for the possibility of the experience, they do not necessitate our own experience of the world. Hence these principles define the space of physical possibilities only: there is no possibility of our having an experience that directly contradicts our constitutive principles. That is why the constitutive approach alone cannot explain how it can be rational to abandon an established conceptual framework ( a "paradigm", a "research programme", etc.) in favor of a new one.

Thus Kant maintained that the Ideas of Reason can only play a regulative rather than a constitutive role. That is why they can be applied heuristically as a guide for our investigations only, but not substantially as the actual inner principle of what we really find out. Reason demands the systematization of our knowledge, it strives for unity. As science advances, it replaces a 'narrower aspect of experience by a broader' one (Kant). Yet in experimental physics maintained Kant - even the principles according to which we perform experiments must themselves always be derived from the knowledge of nature, and hence from the theory. Thereafter, due to theory-laidenness of observations, science sedulously advances by theory unification. And an eminent neo-Kantian of Marburg school Ernst Cassirer underscored that "true unity is never thought in things as such, but in intellectual constructions". In truly Kantian wake he pointed out that unification was a purely regulative demand.

As Kant himself put it in the Appendix to the Dialectic, science must adopt certain ideas of reason as heuristic ('as if") devices to encourage systematic unity.

"The concepts of reason are, as we have said, mere ideas, and of course have no object in any sort of experience, but also do not on that account designate objects that are invented and at the same time thereby assumed to be possible. They are merely thought problematically, in order to ground regulative principles of the systematic use of the understanding in the field of experience in relation to them (as heuristic fictions)" [42] (p.659).

Along these lines, Fölsing (1997) shrewdly noted that Einstein probably first learned to think in terms of his 1905a 'heuristic viewpoint' from his early reading of Kant. Einstein's 'heuristic method' was to make up an assertion from which familiar facts could then be deduced. Note that Einstein's path-breaking, ultra-revolutionary 1905a paper was entitled "Über einen die Erzeugung und Verwandlung des Lichtes betreffenden heuristischen Lesichtspunkt" ("On a Heuristic Point of View Concerning the Production and Transformation of Light").

Yet while carefully dissociating himself from Kantian 'synthetic a priori', Einstein strongly supports the general neo- Kantian epistemological view:

"The following, however, appears to me to be correct in Kant's statement of the problem: in thinking we use, with a certain 'right', concepts to which there is no access from the materials of sensory experiences" [38] (p.22).

So, I reckon that the felicitous notion for comprehending important facets Einstein's 1905 research activity is Kant's concept of systematic Unity of Nature as a regulative idea. This unity, both for Kant and for Einstein, is not an ontological tenet at all. It is meaningless to question whether mother Nature in fact possesses such a unity or not. On the contrary, the idea of unity has incontestable epistemological importance, since systematic unity of nature provides a benchmark of validity for scientific hypothesis that complements the empirical idea of confirmation. Not by a chance Kant [42], p.592) descries the "hypothetical employment of reason", emphasizing once and oft that the confirmation of a hypothesis by its empirical consequences can never endow such a hypothesis with universality, or 'certainty': "In natural science... there is endless conjecture, and certainty is not to be counted upon" [42] (p.608).

Since a given natural - science hypothesis cannot obtain the proof of its truth from 'below', from repeated experimental confirmation, something else is needed. One needs the criterion that can distinguish contingent and unimportant empirical generalizations from genuine profound Laws of Nature, which are endowed with Universality and Necessity. Kantian fruitful idea of the "truth" of a proposition is equivalent to its being a law-like statement.

"Such concepts of reason are not created by nature, rather we question nature according to be deflective as long as it is not adequate to them [...] The hypothetical use of reason is therefore directed at the systematic unity of the understanding's cognition, which, however, is the touchstone of truth for its rules" [42] (p. 592).

Hence from the pile of different uniformities only those can be regarded as having law-like necessity that can be fitted into a unified, systematized general system. Hence in the "Autobiographical Notes", reflecting on his methodological principles, Einstein emphasized that "A system has truthcontent according to the certainty and completeness of its coordination-possibility to the totality of experience. A correct proposition borrows its 'truth' from the truth-content of a system to which it belongs" [2] (p. 13). 


\section{Philosophy International Journal}

It should be noted that the term "totality of experience" points on the other source of Einstein's philosophical inspiration - Duhem's conventionalism [43].

"In sum, the physicist can never subject an isolated hypothesis to experimental test, but only a whole group of hypotheses [...]. Physical science is a system that must be taken as a whole; it is an organism in which one part cannot be made to function except when the parts that are most remote from it are called into play" [6] (p.187).

Or, as a professional epistemologist Willard V.Quine amply enunciated later, "The totality of our so-called knowledge or beliefs, from the most casual matters of geography and history to the profoundest laws of atomic physics or even of pure mathematics and logic, is a man-made fabric which impinges on experience only along the edges. Or, to change the figure, total science is like a field of force whose boundary conditions are experience" [44] (p.345).

Note that it was this 'holistic' efficacious stand that allowed Einstein as early as in 1906 to call into question the widely accepted results of Kaufmann's 'crucial experiments'. These data seemed to support the Abraham-Bucherer theory and to refute the "Lorentz-Einstein" one [20] (p.253); [45] (p.124).

As Einstein had shrewdly put it, the rival theories (e.g. Abraham's electron theory) "have rather small probabilities, because their fundamental assumptions (concerning the mass of moving electrons) are not explainable in terms of theoretical systems which embrace a greater complex of phenomena" [20] (p. 253).

Einstein consented that empirically equivalent alternative theories can be invented for any domain of natural phenomena. Yet if for commited conventionalist a la Pierre Duhem such 'an underdetermination of theory by facts' meant that there can be no ultimately true theory, the Einsteinian train of thought in the Kantian wake not only provided a meaning to the regulative ideal of a final theory. It also illuminated Einstein's significant remarks that despite this underdetermination at any given time there is only one true theory: the theory with the greatest power of unification [45] (p. 226).

Thus Einstein's full involvement in the 1905a paper to the subject of theory of quanta was engendered by its startling unifying possibilities, by its fascinating capacities to arrive at a fusion of Maxwellian electrodynamics and Boltzmann's statistical thermodynamics. Hence in the paper he commences with the heart of what troubled him most the Deep Abyss in the foundations of physics felt most sharply in Lorentz's Electron Theory ( and "H.A.Lorentz [himself] knew this very well', p.37) [2]. How did Einstein intend to eliminate the basic contradiction of his 1905a paper?

While reflecting on Einstein's way out of the predicament, one should take into account that all Einstein's papers from 1901 to 1905 possess one attribute in common: statistical-thermodynamics approach. Thomas S. Kuhn had highlighted that what prompted Einstein to idea of photon was an incessant development of a research program started in 1902, a program "so nearly independent of Planck that it would almost certainly have led to the black-body law even if Planck had never lived" [6] (p. 171). From the start of his scientific career Einstein was deeply impressed by the simplicity and scope of classical thermodynamics. Yet for him thermodynamics included the statistical approach he had imbibed from Boltzmann's thought-provoking works, and so he pioneered to unfold statistical thermodynamics. The result was a series of three papers published in 1902, 1903 and 1904. Expressly they [46-48] provide the clue for understanding his 1905a paper on quanta, his 1905b dissertation, $1905 \mathrm{c}$ work on Brownian motion and $1905 d$ paper on special relativity.

The first significant result consisted in that for physical systems of extraordinary general sort Einstein had provided, by the summer of 1903, both a generalized measure for temperature $\mathrm{T}$ and entropy $\mathrm{S}$, containing some universal constant $\chi$. By the time he completed his 1903 paper, Einstein had understood that $\chi$ could be evaluated in terms of the values of the gas constant and of Avogadro's number. Yet the theory that had led him to the constant was, however, applicable to systems far more general than gases. It should therefore have a correspondingly general physical foundation, reflecting statistical-mechanical nature of the approach that led him to the constant, explaining not only its role as a scale factor for temperature, but also its position as a multiplier in the probabilistic definition of entropy. Physical significance of $\chi$ was the central problem considered in Einstein's third statistical paper "On the General Molecular Theory of Heat", submitted to the "Annalen" in the spring of 1904. The solution of the problem reduced to the phenomena of energy fluctuations. Einstein exhibited that $\bar{\varepsilon}^{2}=2 \chi \mathrm{T} \mathrm{dE} /$ $\mathrm{dT}$, where $\bar{\varepsilon}^{2}$ is a measure of thermal stability of the system, $\mathrm{T}$ - temperature of the system and E its energy. And it was understanding of the constant physical sense that directed his attention to the black-body problem.

"The equation just found would permit an exact determination of the universal constant $\chi$ if it were possible to determine the energy fluctuation of the system. In the present state of our knowledge, however, that is not the case. Indeed, for only one sort of physical system can we presume from experience that an energy fluctuation occurs. That system is empty space filled with thermal radiation" [48]. 


\section{Philosophy International Journal}

At least one more step in the programme of statistical thermodynamics advancement was needed, and Einstein took it in the next, 1905a paper. Its content suggests that Einstein had started to seek a black-body law of his own, and that he had quickly elicited the paradox, evinced in the contradiction between statistical mechanics and maxwellian electrodynamics, and that he had dropped the search for the law in favour of an exploration of the paradox itself. It is clear from the beginning of his already quoted paper [34]. The first part of the 1905a masterpiece came to an end by unfolding the "ultraviolet catastrophe". Yet how did Einstein intended to resolve the paradox?

In the second part of his 1905a paper Einstein uses thermodynamics, statistical mechanics and maxwellian electrodynamics to investigate the domain of empirical reality covered by Wien's radiation law. Einstein takes $\beta=h / k=N h / R$ (R denotes the universal gas constant, $\mathrm{N}$ the number of "real molecules" in one gram-equivalent, $\mathrm{h}$ is Planck's constant and $\mathrm{k}$ is Boltzmann's constant) as undefined constant in 1905a paper and hence he writes $\mathrm{R} \beta / \mathrm{N}$ everywhere instead of $h$. The joint application of the three mature theories, belonging to three profound research traditions of classical physics enables Einstein to draw the following conclusion: if monochromatic radiation of frequency $v$ and energy $E$ is enclosed in the volume $V_{0}$, then the probability $W$ that at any moment all the radiation energy will be discovered in the partial volume $\mathrm{V}$ of the volume $\mathrm{V}_{0}$ is given by

$$
\mathrm{W}=\left(\mathrm{V} / \mathrm{V}_{0}\right)^{\mathrm{E} / \mathrm{hv}}
$$

Yet in the same paper Einstein had previously learned that in the case of $\mathrm{n}$ independently moving particles enclosed in a volume $\mathrm{V}_{0}$ the probability of finding them all momentarily in the subvolume $\mathrm{V}$ is

$$
\mathrm{W}=\left(\mathrm{V} / \mathrm{V}_{0}\right)^{\mathrm{n}}
$$

Comparing equations (i) and (ii), Einstein draws a thrilling conclusion that "monochromatic radiation of small density behaves in thermodynamic respects as though it consists of distinct independent energy quanta of magnitude $h v^{\prime \prime}$.

Thus, the conclusion that radiation in the cavity 'consists' of independent energy quanta follows directly from application of general principles of thermodynamics and statistical mechanics to radiation phenomena.

But in the turn of the XIXth century all the available experimental data, relevant to fluorescence, photoelectricity and photoionization data, could guarantee only indirect verity of quantum hypothesis. Hence, to put to the severe test the ultra-revolutionary hypothesis of quanta, Einstein had to appeal to a "crucial experiment" of a very peculiar, freaky kind. He had to compare the quantum results with the results of another entrenched, 'old' theory contrived independently of the 1905a bizarre hypothesis. Note that this theory had to be sufficiently 'old' to accumulate the results of many experiments. So, if the 1905a paper results had matched the results of fairly different theory, that arose out of substantially different problem situation, they would have provided an especially reliable verification of "photon hypothesis". Let us recall that "A proposition is correct if, within a logical system, it is deduced according to the accepted logical rules. A system has truth-content according to the certainty and completeness of its coordination-possibility to the totality of experience. A correct proposition borrows its 'truth' from the truth-content of a system to which it belongs" [Ein richtiger Satz erborgt seine 'Wahrheit' von dem Wahrheits-Gehalt des Systems, dem er angehört] [2].

In the opposite case the 1905a theory would have been 'falsified' not by a single 'critical experiment' but by a whole multitude of the well-established experimental data. Note that it was this 'holistic' stand that allowed Einstein as early as in 1906 to disregard the results of Kaufmann's "crucial" experiments, which seemed to support the AbrahamBucherer theory and to refute the "Lorentz-Einstein" theory $[20,49]$.

As Einstein had recalled later, the rival theories (e.g. Abraham's electron theory)

"Have rather small probabilities, because their fundamental assumptions (concerning the mass of moving electrons) are not explainable in terms of theoretical systems which embrace a greater complex of phenomena" [20] (p.253).

Thus the next - 1905b - result was decisive for the 1905a verification. In the $1905 \mathrm{~b}$ paper Einstein sedulously perpetrated the principles of Brownian motion that were directly verified by Perrin's experiments.

"My principal aim in this [1905b work on Brownian motion] was to find facts that would guarantee as much as possible the existence of atoms of definite size... The agreement of these considerations with experience together with Planck's determination of the true molecular size from the law of radiation (for high temperatures) convinced the sceptics, who were quite numerous at that time (Ostwald, Mach) , of the reality of atoms" [2] (pp.45-47).

Though the importance of 1905b paper's for the 1905a one was rendered by Einstein much later; he told Max von Laue on 17 January 1952:

"When one goes through your collection of verifications of the special relativity theory, one believes that Maxwell's 


\section{Philosophy International Journal}

theory is firmly established. But in 1905 I knew already with certainty that it leads to the wrong fluctuations in radiation pressure, and consequently to an incorrect Brownian motion of a mirror in a Planckian radiation cavity" [13] (p.177).

This obvious for 1905 Einstein result was rendered to the scientific community only in 1909 when Einstein applied his theory of Brownian motion to a two-sided mirror immersed in thermal radiation. He exhibited that the mirror would be unable to carry out a Brownian motion indefinitely, if the fluctuations in the radiation pressure on its surfaces were solely due to the effects of random waves, as predicted by Maxwell's theory. However only the presence of an additional term, corresponding to pressure fluctuations due to the impact of random particles, insures the continued Brownian motion of the mirror. Einstein demonstrated that similar fluctuation terms in the energy were consequences of Planck's law. He considered such fluctuation phenomena as the strongest argument for ascribing physical significance to the hypothetical light quanta [50]. Only after this quaint "crucial thought experiment", that is only after the 1905b paper could Einstein look forward for investigating the startling consequences of his light quantum hypothesis, and so he returned to his half-forgotten "unsere Arbeit uber die Relativbewegung", eine "kapitale Abhandlung". This manuscript was destined to become special relativity. So far, so good.

"If the monochromatic radiation (of sufficiently small density) in the sense of entropy dependence upon volume behaves itself as a discontinuous medium, consisting of energy quanta $\mathrm{R} \beta \mathrm{v} / \mathrm{N}$, a question occurs: if they are not the laws of creation and conversion of light such as if it consists of similar energy quanta?" [4] (p.236).

That is the question cautiously put up by Einstein at the end of $\S 6$ of his 1905a. But it was the ether conception that turned out to be a substantial snag. It prevented positive answer and put insurmountable obstacles in exerting Einstein's statistical-thermodynamics programme. Indeed "mechanical and purely electromagnetic interpretations of optical and electromagnetic phenomena have in common that in both cases electromagnetic field is considered as a special state of the hypothetical medium filling all the space. Namely in that point two interpretations mentioned differ radically from Newton's emission theory, in which light consists of moving particles. According to Newton, space should be considered as possessing neither ponderable matter, nor light rays, i.e. absolutely empty" [4] (p.236).

To invent a quantum theory of radiation, one needs electromagnetic fields as independent entities that can be emitted by the source " just as in Newton's emitting theory" (i.e. the energy transmitted in a process of emission should not be dissipated in space, but should be completely preserved until an elementary act of absorption). Yet within the Lorentz programme an electromagnetic field is considered as a specific state of ether - a state of medium that is continuously distributed in space. In such a medium an elementary process of radiation is connected only with a spherical wave.

Nevertheless, aversion to the ether and acceptance of emission theory should lead to Walter Ritz's 1908 artful 'ballistic hypothesis': velocity of quantum should depend on the velocity of its source. In Ritz's theory the velocity of light is not constant, but is equal to $\mathrm{v}+\mathrm{c}$, where $\mathrm{v}$ is a relative velocity of the observer and the source.

Later, in April of 1922, Einstein had confessed to Viscardini:

"I rejected this [emission] hypothesis at that time, because it leads to tremendous theoretical difficulties (e.g. the expectation of shadow formation by a screen that moves relative to the light source)" [13] (p.182).

Thus Einstein, by contrast, never thought of downing Maxwell's theory, just as Newton, the inventor of the emission theory, did not reject the wave theory 300 years earlier. In the 1905a paper Einstein had especially underscored that "Wave theory operating with point continuous functions is excellently justified when describing purely optical phenomena and perhaps would not be replaced by another theory" [4] (p.237).

In Lorentz's theory this predicament was absent. Indeed, in the reference frame that is at rest relative to the ether light propagates with constant velocity independent of the velocity of the source. Hence, if one wants to give up the idea of ether, but to come to terms with Maxwell's theory at the same time, s/he should disown ballistic hypothesis and "raise to the rank of a principle the validity of the law of constancy of light velocity for all inertial frames" [51]), i.e. postulate a special "principle of constancy of velocity of light"(I).

The second basic principle of STR - "the principle of relativity"(II) - follows immediately from the proposition that there is no luminiferous ether and, consequently, no absolute system of reference.

Just as Einstein underscored in the "Autobiographical Notes", "Reflections of this type [i.e. on molecular structure of radiation ] made it clear to me as long as shortly after 1900 , i.e. shortly after Planck's trailblazing work, that neither mechanics nor electrodynamics could (except in limiting cases) claim exact validity. By and by I despaired of the possibility of discovering the true laws by means of constructive efforts based on known facts.The longer and the 


\section{Philosophy International Journal}

more despairingly I tried, the more I came to the conviction that only the discovery of a universal formal principle could lead us to assured results.The example I saw before me was thermodynamics" [2] (p.51).

The latter point needs further elucidation at the expense of delving into Mach's pre-eminent "Mechanics" as the main source of 1905 Einstein's information on the history of physics. The most profound case study of the interconnection between the principle of economy of thought and second law of thermodynamics in "Mechanics" is Stevinus's (1548-1620) fundamental theoretical scheme of statics. In his immaculate "Hypomnemata Mathematica" Stevinus pioneered in unfolding the mechanical properties of the inclined plane. He tried to set up a general theoretical principle and then to investigate the partial cases that can be easily treated by quantitative means. To provide the pivotal gedankenexperiment, necessary to set up his general principle, Stevin invents a triangular prism with no horizontally placed edges. Over the prism he lays an endless string on which 14 balls of equal weight are strung and tied at equal distances apart. (The string can be easily replaced by an endless uniform chain).

This chain will either be in equilibrium or not. If we assume the latter to be the case, the chain, since the conditions of the event are not altered by its motion, must, when once actually in motion, continue to move forever. In other words, it must provide perpetual motion, which Stevin considers blatantly absurd. Therefore only the first case is conceivable and the chain always remains in equilibrium.

It is important for Mach that in the main premise from which Stevin starts, that the endless chain does not move, there is contained only a purely instinctive cognition. He feels at once, and we with him, that we have never seen anything like a motion of the kind referred to. This conviction has so much logical cogency that one eagerly accepts the conclusion drawn from it respecting the law of equilibrium on the inclined plane without the thought of an objection, although the law is shrewdly presented as the simple result of the experiment. We cannot be surprised at this when we note that all results of experiment are obscured by adventitious circumstances (as friction, etc.), and that every conjecture as to the conditions which are determinative in a given case are liable to error. So Stevinus ascribes to instinctive knowledge of this sort a higher authority than to simple, manifest, direct observations! As a result, we are faced with the following essential question: whence does this higher authority come? If one recalls that scientific demonstration , and scientific criticism generally can only have sprung from the consciousness of the individual fallibility of investigators, the explanation is apparent. We feel clearly, that we ourselves have contributed nothing to the creation of this startling
"Instinctive Knowledge", that we have added to it nothing arbitrarily, but that it exists in strict independence of our participation.

According to Mach, Stevinus's deduction is one of the rarest 'fossile indicators' that we possess in the history of mechanics, and throws a fascinating light on the process of the formation of science generally, on its rise from instinctive knowledge.

Nevertheless, every experimenter can daily underscore in his own person the guidance that Instinctive Knowledge furnishes him. If he succeeds in abstractly formulating what is contained in it, he will as a rule have made a significant advance in science. And it is perfectly certain for the author of "Mechanics" that the amalgamation of the strongest instinct with the greatest power of abstract formulation alone constitutes the great natural inquirer [p. 27] [21].

Though how does this "instinctive knowledge" originate and what is its structure?

Everything which one observes in nature imprints itself uncomprehended and unanalysed in his percepts and ideas. In these accumulated experiences he possesses a 'treasure store' which is ever close at hand and of which only the small part is embodied in fine articulate thought. The circumstance that it is far easier to appeal to these experiences than it is to nature herself, and they are, notwithstanding this, free from all subjectivity, invests them with a high value. "It is a peculiar property of instinctive knowledge that it is predominantly of a negative nature" [21] (p. 28). We cannot so well say what must happen as we can what cannot happen, since the latter alone stands in devastating contrast to the obscure mass of experience in us in which single characters are not distinguished. Moreover, maintains Mach, the other attribute that is no less important for the philosophy of science consists in that the reasoning of Stevinus has such a strong influence upon us because the result at which he arrives obviously contains more than the assumption from which he starts.

Nay, it often happens in the course of the advancement of science that a new principle perceived by some researcher in connection with a fact, is not immediately recognized and set up in all its generosity. If, throughout all facts, we clearly indicate and discern a principle which, though not admitting of proof, can yet be known to dominate, we have advanced much farther in the consistent view of nature than if we suffered ourselves to be overawed by a specious demonstration [21] (p. 82).

In my judgement, all the above mentioned StevinMach fascinating recipes where ingeniously implemented by Einstein in formulating the basic STR principle - the principle of relativity. Though due to ultra-revolutionary 


\section{Philosophy International Journal}

and extremely speculative nature of light-quanta hypothesis he could not dare to reveal the link with the 1905a paper directly. Hence he used all the Stevin-Mach technique of conviction at hand to render his electrodynamics of moving bodies in phenomenological wake. One should especially pay respect to the negative character of the relativity principle and the manner of its connections with experiments and observations that is closer to subtle conviction technique of instinctive knowledge than to coarse inductive way of inference. Behold at the beginning of the STR paper:

"Examples of a similar kind, and the failure of attempts to detect a motion of the earth relative to the 'light medium', lead to the conjecture that not only in mechanics, but in electrodynamics as well, the phenomena do not have any properties corresponding to the concept of absolute rest, but that in all coordinate systems in which the mechanical equations are valid, also the same electrodynamic and optical laws are valid, as have already been shown for quantities of the first order. We shall raise this conjecture (whose content will be called 'the principle of relativity' hereafter) to the status of a postulate and shall introduce, in addition, the postulate, only seemingly incompatible with the former one, that in empty space light is always propagated with a definite velocity $\mathrm{V}$ which is independent of the state of motion of emitting body" [5] (p.140).

Appeal to instinctive knowledge easily explains the fact that the special relativity paper by rights stands out in all the world scientific literature for the complete lack of quotations. And since, according to the "Autobiographical Notes", Einstein's new hybrid theory was created as a result of inevitable encounter of Newtonian mechanics and Maxwellian electrodynamics, its basis should consist of a minimum of two postulates, (I) the first drawn from classical mechanics (the principle of relativity) and (II) the second one transferred from the Maxwell-Lorentz electrodynamics (the principle of the constancy of light). Namely,

(I) "Classical mechanics, of which it could not be doubted that it holds with a close degree of approximation, teaches the equivalence of all inertial systems or inertial 'spaces' for the formulation of natural laws, i.e., the invariance of natural laws with respect to the transition from one inertial system to another" (Einstein [37], p.369).(II) "This [the special theory of relativity] takes over from the theory of MaxwellLorentz the assumption of the constancy of the velocity of light" [36] (p. 370).

On my view, to understand the genesis of both postulates, and especially the first one, one can appeal to the recipes of another Mach's contemporary and accomplice:

"We recognize a correct principle by the facility with which it straightens out the complicated difficulties into which the use of erroneous principles brought us. If, therefore, the idea we have put forth is correct, namely, that comparison is established necessarily between the whole of theory and the whole of experimental facts, we ought in the light of this principle to see the disappearance of the obscurities in which we should be lost by thinking that we are subjecting each isolated theoretical hypothesis to the test of facts [43] (p. 208).

The two postulates, (I) + (II), the relativity principle plus the principle of constancy of velocity of light, are quite sufficient, according to Einstein, to work out the electrodynamics of moving bodies. Yet, since "the theory based on these two principles should not to lead to contradictory results, one must renounce the customary rule of addition of velocities" [52] (p. 125).

And namely that was done in the $1905 \mathrm{~d}$ paper «On the Electrodynamics of Moving Bodies", published several months after the 1905a paper. Einstein had revealed the hidden assumption - the basis of the Galileo addition law - that the statements of time, as well as of the shapes of moving bodies have the sense independent of the state of motion of the reference frame. He highlighted that the acceptance of the 'principle of relativity' together with the 'principle of constancy of light' is equivalent to significant modification of the simultaneity concept and to clock delay in moving reference frame.

It should be emphasized that in no ways 1905 Einstein was an idle thinker reflecting on the essence of space and time. He was forced to abstract philosophical reasoning on the nature of space and time by his common research practice, by a mundane physical problem of reconciling classical mechanics (the Principle of Relativity) with classical electrodynamics (the Light Constancy Postulate) .

Hence, at least in that case, Einstein's application of Hume and Mach's eminent philosophical writings was 'highly selective' [53] (p.359). His ultimate goals were not so much to apprehend Hume's and Mach's lofty reflections as to find in them efficacious ideas that may be fruitful in his mundane research.

Well, if all said before is true, the following question should be elicited: why Einstein in the 1905d relativity paper did not cite his 1905a paper on light quanta? To provide a sober answer one has to dwell into Einstein's 1905 correspondence. Writing to his close friend Conrad Habicht in 1905 and sending him the thrilling results of his labours at that time, Einstein proudly called his light quanta paper "very revolutionary", while the relativity paper was humbly characterized as "interesting in its kinematical part". So, reference in the paper, making substantial changes mainly of metaphysical character, on the hypothesis that had 


\section{Philosophy International Journal}

already rendered revolutionary changes and had blatantly contradicted Maxwell's theory, could hardly make the arguments stronger. For instance, in a 1910 paper on the theory of thermal radiation Max Planck eloquently advised:

"It appears to me that utmost caution against the new Einsteinian corpuscular theory of light would be warranted... The theory of light would be thrown not decades, but centuries, to the time when Christian Huygens dared to take up his fight against Newton's overpowering emission theory... And all the accomplishments, which are among the proudest successes of physics, indeed of scientific research overall, are supposed to be sacrificed for the sake of some still quite conrestable observations? Heavier artillery would really need to be run out to sway this, by now, very firmly founded edifice of electromagnetic light theory" [54] (p. 21).

Einstein himself at the first Solvay Congress had to recognize through his teeth "provisional character of this concept [light quanta] which does not seem reconcilable with the experimentally verified consequences of the wave theory" [55] (p. 884). The situation was even more dramatic since direct experimental evidence in favour of existence of light quanta was absent. It famously appeared only circa 1923 (the Compton effect). Being considered independently, the STR did not explain any new experimental fact. Predictions of the Lorentz theory were identical to that of the STR, so that it would not be possible in any case to distinguish between the two rival theories on experimental grounds. Moreover, most of Einstein's contemporaries had vividly discussed on the "Lorentz-Einstein electron model", reflected on the "principle of relativity of Lorentz and Einstein", and so forth. At the time of publication of Lorentz's second order theory (1904) the only data available to test these theories were Kaufmann's thrilling measurements of the masses of slowly moving electrons. But they were initially interpreted by the scientific community as contradicting both STR and Lorentz's theory. It took a whole year for Einstein to answer on Kaufmann's paper. One can only imagine how the STR was evaluated by the scientific community in 1905 - 1906! Furthermore, Einstein sagaciously did not promulgate the connections between 1905a and 1905d until 1909. However, without this links the STR bizarre postulates can be evaluated as ad hoc hypotheses. And they were! (The response of Henri Poincaré and of the French school is the most apparent example). So, being confronted with many ingenious rival theories, why did Einstein preferred special theory of relativity? What undisguised advantages did it possess over the artful contrivances of Lorentz, Ritz and others?

The answer again leads one to Einstein's unificationist approach. The unificationist stand highlights Einstein's seemingly puzzling remarks that despite the underdetermination at any given time there is only one correct theory: the theory with the greatest power of unification at that time $[45,39]$.

We are usually told that in constructing the STR Einstein had contrived a "theory of principle", rather than a "constructive theory". However, things are not that simple. Indeed, it was Einstein himself who moulded a thoughtprovoking distinction between 'principle' theories and 'constructive' ones. Constructive theories strive to "build up a picture of the more complex phenomena out of the materials of a relatively simple formal scheme from which they start out" [1] (p. 49). An example of a constructive theory is kinetic theory that tries to reduce mechanical and thermal properties of gases to movements of molecules; the second example is Einstein's light quanta hypothesis. On the other hand, principle theories do not start out from hypothetical constructions, but rather from empirically ascertained principles.

"Thus the science of thermodynamics seeks by analytical means to deduce necessary conditions, which separate events have to satisfy, from the universally experienced fact that perpetual motion is impossible". In explicitly Kantian terms Einstein in 1919 distinguishes between the abovementioned kinds of theories: "principal theories employ the analytic, not the synthetic method" [1] (p. 50).

It is to his boon companion Michele Besso that Einstein dedicated the only acknowledgement in his 1905d paper, the paper that stands out for its lack of any reference to the literature. Nay, in the $1905 \mathrm{~d}$ paper "the failure of attempts to detect a motion of the earth relative to the "light medium"' is taken as evidential support only for one of the two STR postulates - for the 'Principle of Relativity'. The 'Light Postulate' is introduced almost parenthetically, without any serious discussion of its experimental grounds. Only in subsequent $1905 \mathrm{e}$ paper, while recapitulating the $1905 \mathrm{~d}$ results, Einstein drops a telling phrase: "the principle of the constancy of the velocity of light used there is of course contained in Maxwell's equations" [57] (p. 172). Yet one should take into account that for him the $1905 \mathrm{~d}$ paper was only a provisional construct, a mere milestone in realizing the reconcilement programme. Einstein clearly understood that "a physical theory can only be satisfactory, if its structures are composed of elementary foundations. The theory of relativity is just as little ultimately satisfactory as, for example, classical thermodynamics was before Boltzmann had interpreted the entropy as probability" $[50,58]$.

So, the bold proposition that the $1905 \mathrm{~d}$ paper contstututed a theory of principle is merely half of the truth. In reality the $1905 \mathrm{~d}$ theory was only a constructive one that diligently posited itself as a theory of principle. (Possibly due to tactical reasons for Einstein probably strived to save the 
STR from the scathing criticism directed against the light quanta). That is why two years later, trying to expose the STR foundations to broad physical community, Einstein mildly described his relativity theory as "an attempt to summarize the studies that have resulted to date from the merger of the Lorentz's theory and the principle of relativity" [59] (p.253).

Though the situation could not last over a long period of time. Einstein had to throw his cards up and to reveal the subtle link between his 1905a and 1905d innovations four years later. In 1909, in Salzburg, he made an overview report at the 81-st meeting of German Natural Scientists and Physicians under the expressive title "On the Development of our Views on the Nature and Structure of Radiation". It was practically the first effort and opportunity to render almost all his various papers as a whole. And it represented one of the first Einstein's public reports dedicated to expounding of the STR foundations. The report commences with a brief recapitulation of luminiferous ether theory that ends by an intriguing question: "However, today we must regard the ether hypothesis as an obsolete standpoint".

Why? What I want to punctuate is that for the answer Einstein appeals not to the Michelson-Morley or Fizeau experiments, but emphasizes that

"It is even undeniable that there is an extensive group of facts concerning radiation that shows that light possesses certain fundamental properties that can be understood far more readily from the standpoint of Newton's emission theory of light than from the standpoint of the wave theory. It is therefore my opinion that the next stage in the development of theoretical physics will bring us a theory of light that can be understood as a kind of fusion of the wave and emission theories of light" [58] (p. 379).

And the abovementioned proverbial experiments are brought into consideration only in the context of the "cardinal aspect in which the electromagnetic theory agrees with, or, more accurately, seems to agree with the kinetic theory" (Einstein [58], p. 379; my italics).

\section{Discussion}

The thrust of the paper consists in that to conceive the important facets of Einstein's 1905 scientific creativity and all his 1905 papers as a whole as well as the subtle order of their presentation one should resort to Planck's and Einstein's strenuous efforts to reconcile the profound and entrenched research traditions of classical physics. Hence the crux of the present account is to provide further support to the epistemological theory-change model [60]. According to the model, radical breakthroughs in science were not due to ingenious inventions of new paradigms or creation of new ideas ex nihilo, but rather to the long-term and harrowing processes of the reconciliation, interpenetration and intertwinement of 'old' research traditions preceding such breaks. Just to quote Pierre Duhem:

"In the course of this long and laborious birth, we can follow the slow and gradual transformations through which the theoretical system evolved; but at no time can we see a sudden and arbitrary creation of new hypotheses" [43] (p. 252).

In creating the theory of light quanta and the special theory of relativity Einstein was operating according to a strong belief in the necessity for unity in science, as well as the coincidence of both constructing theory and integrating intuition of Principle. Hence sagacious identifying and dexterous resolving the paradox revealing the contradictions between the basic research traditions turns out a key part of the scientific method. It was exhibited that Einstein's method was construction of theory within the guidance of intuitive principles sometimes beginning with construction, sometimes with principle, but always demanding their consistency, and clear identification of well-documented paradox that forces us to consider a larger view of Nature's laws.

And to comprehend the importance of the latter one should consider Mach's principle of the economy of thought that governed Einstein's thought through and through all his life. Nevertheless, this is not to maintain that 1905 Einstein was an obdurate Machian incapable to draw upon the rival epistemological sources.

Nay, for instance, in profound "Physik und Realität", published in 1936, i.e. in a work that represents one of the vertices of his philosophical activity, Einstein takes the history of mechanics in quite the opposite from the author of "Die Mechanik" way [51] (p.302). He contends that the significant divergences of opinion with Mach sprung out from stubborn development of atomic theory by Einstein through the 1905 scrutinizing of Brownian motion [61]. Hence the advancement of similar idea of 'atoms of light' [4] can be considered as a part of the abovementioned activity. Yet in my judgement, to understand the more profound reasons of the abovementioned divergences one has to turn face to face to Einstein's true overall philosophical creed.

All in all, his standpoint can be characterized as 'eclecticism', and one cannot elude considering the famous passage from Einstein's stupendous 1949 "Reply to Criticism" where he openly acknowledges his overall eclectic standpoint [62] (p. 684). Yet I support Don Howard's felicitous claim that more thoroughly Einstein's own philosophy of science 
can be characterized as a quaint fusion of the elements drawn from sources as diverse as "Machian empiricism, Duhemian conventionalism and neo-Kantianism" [40].

The influences of Machian empiricism on 1905 Einstein creativity were considered earlier. As for neo- Kantianism, its influence on 1905 Einstein is not limited by the regulative principles epistemology. The 1905a light quanta hypothesis turns out a constructive model of radiation; so in the 1949 Autobiographical Notes Einstein recalled of Mach's legacy: "He [Mach] did not place in the correct light the essentially conctructive and speculative nature of all thinking and more especially of scientific thinking; in consequence, he condemned theory precisely at those points where its constructive-speculative character comes to light unmistakably, such as in the kinetic theory of atoms" [2] (p. 13).

Likewise, in a famous letter to Michele Besso of January 1948 Einstein admits that

"I see his [Mach's] great service as residing in the fact that he dispelled the dogmatism that reigned in the foundations of physics in the $18^{\text {th }}$ and $19^{\text {th }}$ centuries. Especially in the "Mechanik" and the "Warmelehre", he sought to show how concepts grow out of experience. He convincingly defended the view that these concepts, even the most fundamental ones, obtain their justification only from experience...I saw his weakness as residing in the fact that he more or less believed that science consists in the mere "ordering" of empirical materials; i.e. he misunderstood the free, constructive element in the formation of concepts. In a sense, he believed that scientific theories arise through discovery and not through invention" [16] (pp. 390-391).

The constructive character of light quanta hypothesis also brings Einstein's thought closer to Kantian epistemology as was already punctuated by many Einstein scholars. For instance, in Victor F. Lenzen's acute essay “Einstein's Theory of Knowledge" which Einstein himself characterized as "convincing and correct in everything it says", it is contended that "In so far as he acknowledges mathematical objects to be constructions, the theory of Einstein reminds one of Kant who held that objects of mathematics were constructed in pure intuition" [63] (p.380).

In his bona fide 1949 review of Einstein's epistemology Victor F.Lenzen punctuated that during the second half of the XIX th century many scientists - but Ernst Mach particularly -considered the ultimate goal of physical science as the particular representation of processes through concepts inductively derived from sense experiences. Yet for Einstein the consistent application of Newtonian mechanics carried theoretical physics far beyond the pure phenomenological stance.
Einstein many a time and oft indicated that the main concepts of science are free creations of the human mind. In an eloquent letter to Schlick from November 1930, Einstein famously contended: "Physics is an attempt to construct conceptually a model of the real world as well as its lawgoverned structure" [64] (p.25).

In that respect Einstein's standpoint is evidently close to Kant. Respectively the positive drive for creative work could be discovered in Kant's constructivist foundation for scientific knowledge that restricted science to the realm of appearences stating that a priori knowledge of things in themselves is impossible. Much later Einstein pointedly confessed:

"I did not grow up in the Kantian tradition, but came to understand the truly valuable which is to be found in his doctrine, alongside of errors which today are quite obvious, quite late. It is contained in the sentence: 'The real is not given [gegeben] to us, but put to us [aufgegeben]' [by way of a riddle] [65].

Even mathematics - asserted to be most stable and certain because of its being analytical - was understood by Kant as an a priori synthetic judgement. As he pointed out in "Prolegomena" [66], the hallmark of pure mathematical cognition, differentiating it from all other a priori cognition, is that it must advance not from concepts, but through the construction of concepts. Because pure mathematical cognition, in its propositions, must therefore go beyond the concept to that which is contained in the intuition corresponding to it, its propositions can and must never spring out of the analysis of concepts, i.e. analytically, and so are one and all synthetic.

The Kantian doctrine of the intuitive nature of mathematics means the limiting of mathematics to those objects that are constitutable [Konstruierbar]. 'Intuitive' is equal to 'constitutable'. As Ludwig Wittgenstein has later contended in genuinely Kantian terms, "But the mathematician is not a discoverer, he is an inventor".

Kant considered objectivity of science as resulting from the way in which the turmoil of sensibility was regularized under the categories of the understanding with a help of spatial and temporal categories. That is why mathematics can so effectively exhibit objective reality: for Kant mathematical constructs are related to the pure intuitions of space and time.

Hence mathematical statements are true in virtue of their application in experience to exhibit the behavior of empirical bodies. While mathematical judgements are produced via construction in pure intuition, they are taken as cognitions only because they are necessary connected to experience 
in the sense that geometrical space was contemplated as a condition of appearance [42] (p.196).

Since the abstract objects of a theory are constituted by the laws of the theory, the abovementioned objectivity is related not to the existence of things but to the objective validity of relations. Respectively, in the 1905 a paper, while carefully constructing the mathematical abstract object "light quanta" out of the basic objects of maxwellian electrodynamics and statistical thermodynamics, Einstein was not bothered with grasping the 'essences' of radiation phenomena. He strived with the problems of reconciling the interrelations of different classical physics research traditions, i.e. maxwellian electrodynamics, statistical mechanics and thermodynamics. Remember that in their Proposal for Einstein's Membership in the Prussian Academy of Science, M. Planck et al. had pointed out that

"Einstein has a special talent for getting to the bottom of other scientists' newly emerging views and assertions, and for assessing their relationship to each other and to experience with surprising certainty" [10] (Doc. № 445, p.338; my italics).

It is a platitude that Einstein's philosophical evolution after the General Relativity was achieved carried him further and further from Humean and Machian half-digested empiricist bias toward profound neo-Cantian tradition represented by such luminaries as Weyl, Eddington, Cassirer, Husserl et al. and the corresponding mathematical speculative methodology embodied in a sequence of unified theories. Thus I do not maintain that Einstein of 1905 was an obdurate (neo) Kantian, vehemently trying to implement the abstract tenets of "Critique" into his everyday research practice. Yet, in my view, the Kantian roots (which need to be trialed by future research) of Einstein's subsequent efforts lie in his 1905 activity connected with his fruitful attempts to reconcile maxwellian electrodynamics and statistical thermodynamics.

Nevertheless, inspite of the dominantinfluence of Kantian epistemology, one should not ignore Einstein's sympathy for Pierre Duhem's brand of conventionalism. Though Duhem's masterpiece "The Aim and Structure of Physical Theory" was favorably received when it first appeared in 1906, and at the time of the second edition in 1914, two Duhem's articles, expounding the pivotal ideas of the book, appeared in the "Revue de Philosophie" already in 1904-1905. The crux of Duhem's book consisted in the assertion that

"A physical theory is not an explanation. It is a system of mathematical propositions, deduced from a small number of principles, which aim to represent as simply, as completely, and as exactly as possible a set of experimental laws" [43] (p.19).
As for Albert Einstein, when, in the fall of 1909, he left his salutary job at the patent office in Bern and returned to Zurich to take up his academic position at the University of Zurich, he happened to rent an apartment at Mousonstrasse 12, directly upstairs from his old friend Friedrich Adler.It is quite important that just one year earlier Friedrich published his German translation of Duhem's "La Theorie Physique: son Objet et sa Structure". In one of the letters of this time (1909, to Victor Adler) Friedrich Adler frankly admitted that

"The more I speak with Einstein - and that happens fairly often - the more I see that my favourable opinion of him was justified. Among contemporary physicists he is not only one of the clearest, but also one of the most independent minds, and we are of one mind about questions whose place is generally not understood by the majority of other physicists" [64] (p.7).

Einstein's immersion into Duhem's holism is faintly indicated by the 1910-1911 "Lecture Notes for Course on Electricity and Magnetism", University of Zurich, winter semester 1910-1911, where he operates with typically Duhemean notions of the "totality of experience", etc. [64]. Yet, on my view, one can proceed further stating that for Einstein Duhem's conventionalism was a bridge connecting two quite disparate subjects of Machian crude empiricism and Kantian academic apriorism and transcendentalism. For instance, in the Appendix to "The Aim and Structure of Physical Theory" Duheme states as "the great fact summarizing the whole history of science" the diversity fusing into more comprehensive and more perfect unity. Thus if a physicist "yields to the nature of the human mind, which is repugnant to the extreme demands of positivism [...] he will note that physical theory through its successive advances tends to arrange experimental laws in an order more and more analogous to the transcendal order according to which the realities are classified, that as a result physical theory advances gradually toward its limiting form, namely that of a natural classification, and finally that logical unity is a characteristic without which physical theory cannot claim this rank of a natural classification" [43] (pp. 296-297).

Furthermore, the Appendix concludes by a rhetorical question

"does theory tells us something concerning reality which experiment has not taught us and could not possibly teach us, that is, something transcending empirical knowledge? If we must answer this last question affirmatively, we shall be able to say that physical theory is true and that it has value as knowledge" [43] (p.326).

Yet in already-quoted letter to Max Born Einstein unwinds the subtle relations between Kantian and conventionalist epistemologies in the following way:

"I am reading Kant's "Prolegomena" here, among other things, 
and am beginning to comprehend the enormous suggestive power that emanated from the fellow and still does. Once you concede to him merely the existence of synthetic apriori judgements, you are trapped. I have to water down the " $a$ priori" to conventional, so as not to have to contradict him, but even then the details do not fit".

To recapitulate, Einstein was apparently influenced by Hume, Mach, Poincaré, Duhem, et al., and this is evinced in numerous documents - letters, lectures, oral communications, etc. relating to different periods of his life. Nevertheless, if one delves into his scientific papers, trying to elucidate Einstein's modus operandi, one finds out sober reasons to believe that actually, at least in 1905, in his mundane research practice, he had held such an epistemological stand that can be characterized as a quaint fusion of Machian, conventionalist and Kantian epistemologies. And the most substantial Machian concept crucial to comprehend Einstein's 1905 activity as a whole is Mach's principle of economy of thought but taken in the context of intuitive knowledge doctrine. Hence Einstein renounced the notorious ether notion not because it was a metaphysical straw man, an idle concept, an obsolete superfluous contraption, but since it turned out a flagrant blemish for efficacious reconcilement of maxwellian electrodynamics and statistical thermodynamics that promised to pave a gallant way to the theory of quanta.

\section{References}

1. Van Dongen J (2010) Einstein's Unification. Cambridge: Cambridge University Press.

2. Einstein A (1949a) Autobiographical Notes. In: Schilpp PA (Ed.), Albert Einstein: Philosopher-Scientist, Evanston, IL, 1-2: 1-14.

3. Pais A (1982) Subtle is the Lord. The Science and Life of Albert Einstein. Oxford: Oxford University Press.

4. Einstein A (1905a) Über einen die Erzeugung und Verwandlung des Lichtes betreffenden heuristischen Gesichtspunkt. Ann Phys 17: 132-48. English translation by Anna Beck In: The Collected Papers of Albert Einstein (1989) The Swiss years: writings, 1900 - 1909. Princeton, New Jersey: Princeton University Press, 2: 86-103.

5. Einstein A (1905d) Zur Elektrodynamik bewegter Körper. Ann Phys 17: 891-921. English translation In: The Principle of Relativity, Dover, New York, 1923. See also the translation of Anna Beck in: The Collected Papers of Albert Einstein (1989) The Swiss years: writings, 1900 1909. Princeton, New Jersey: Princeton University Press 2: $140-171$.

6. Kuhn TS (1978) Black-Body Theory and Quantum
Discontinuity, 1894-1912. Oxford and New York: Oxford University Press.

7. Planck Max (1910) Acht Vorlesungen uber theoretische Physik. Leipzig: Hirzel. Originally delivered at Columbia university, 1909, and translated as "Eight Lectures on Theoretical Physics by Wills AP, New York, Columbia University Press.

8. Planck Max (1906) Vorlesungen uber die Theorie der Warmestrahlung. $1^{\text {st }}$ (Edn.), Leipzig: JA Barth.

9. Nugayev RM (2015) Communicative Rationality of the Maxwellian Revolution. Foundations of Science 20(4): 447-478.

10. Einstein A (1987) The Collected Papers of Albert Einstein. The Early Years, Stachel J (Ed.), Princeton: Princeton University Press, 1: 1879-1902.

11. Hertz H (1884) Ueber die Beziehungen zwischen den Maxwell'schen elektrodynamichen Grundgleichungen und den Grundgleichungen der gegnerischen Elektrodynamik. Annalen der Physik und Chemie, 23: 84-103.

12. Albert Einstein, Mileva Marić (1992) The Love Letters. JJürgen Renn, Robert Schulman (Ed. and with an introduction). Syawn Smith (Transl). Princeton, NJ: Princeton University Press.

13. Rynasiewicz R (2000) The Construction of the Special Theory: Some Queries and Considerations. In: Howard D, Stachel J (Eds.), Einstein. The Formative Years, Boston: Birkhauser, pp: 159-201.

14. Einstein A(1905c) Über dievon der molekularkinetischen Theorie der Wärme geforderte Bewegung von in ruhenden Flüssigkeiten suspendierten Teilchen. Ann phys. 17: 123-134, English translation by Anna Beck In: The Collected Papers of Albert Einstein. Vol. 2. The Swiss years: writings, 1900 - 1909. Princeton, New Jersey: Princeton University Press.

15. Seelig Carl (1960) Albert Einstein. Leben und Werk Eines Genies Unserer Zeit.

16. Speziali P (1972) Albert Einstein-Michele Besso: Correspondence. Paris: Hermann.

17. Poincaré H (1902/1905) Science and Hypothesis. Repr. London and Newcastle-on-Tyne: The Walter Scott Publishing Co.

18. Howard D, Stachel J (2000) Einstein. The Formative Years, 1879-1909. Boston: Birkhauser. 


\section{Philosophy International Journal}

19. Darrigol 0 (2001) Electrodynamics from Ampere to Einstein. Oxford: Oxford University Press.

20. Holton G (1968) Mach, Einstein and the Search for Reality. Daedalus 97: 636-673.

21. Mach E (1893/1999) The Science of Mechanics: A Critical and Historical Account of its Developments. McCormmach TJ (Transl). La Salle: Open Court.

22. Frank Ph (1949) Einstein, Mach and Logical Positivism, In: Schilpp PA (Ed.), Albert Einstein: PhilosopherScientist, Evanston, IL, 1-2: 271-286.

23. Tolman R (1912) Some Emission Theories of Light. Phys Rev 35: 136-143.

24. Slavov M (2016) Empiricism and Relationism Intertwined: Hume and Einstein's STR. Theoria 31(2): 247-263.

25. Planck M (1897a) Uber irreversible Strahlungsvorgange. Erste Mitteilung. Berl Ber, pp: 7-68.

26. Planck M (1897b) Uber irreversible Strahlungsvorgange. Zweite Mitteilung. Berl Ber, pp: 715-717.

27. Planck M (1897c) Uber irreversible Strahlungsvorgange. Dritte Mitteilung. Berl Ber, pp: 1122-1145.

28. Planck M (1898) Uber irreversible Strahlungsvorgange. Vierte Mitteilung. Berl Ber, pp: 57-68.

29. Planck M (1899) Uber irreversible Strahlungsvorgange. Funfte Mitteilung (Schluss). Berl Ber, pp: 440-480.

30. Planck M (1900a) Uber irreversible Strahlungsvorgange. Annalen der Physik 1: 69-122.

31. Planck M (1900b) Zur Theorie des Gesetzes der Energieverteilung im Normalspectrum. Verh D D Phys. Ges 2: 237-245 (Transl by Ter Haar in 1967).

32. Dugas Rene (1959) La theorie physique au sens de Boltzmann et ses prolongements modernes. Paris, Editions de Griffon.

33. De Broglie Louis (1962) Mysterious constanth - Max Planck's celebrated discovery. In: Following the Paths of Science. Moscow, Izdatelstvo Inostrannoy Literaturi (Foreign Literature Publishing House), pp.139-146.

34. Ter Haar D (1967) The Old Quantum Theory. Oxford: Pergamon Press.

35. Mach E (1897/1984) The Analysis of Sensations and the Relation of the Physical to the Psychical. Williams CM ((Transl)). La Salle: Open Court.
36. Einstein A (1940/1954) The Fundaments of Theoretical Physics, In: Ideas and Opinions, 323-330, New York: Crown Publishing Inc.

37. Einstein A (1933/1954) On the Method of Theoretical Physics. Reprinted In: Ideas and Opinions, New York: Crown Publishing Inc, pp: 277-283.

38. Einstein A (1944/1954) Remarks on Bertrand Russell's Theory of Knowledge. In: The Philosophy of Bertrand Russell. Paul Arthur Schilpp, Evanston, Illinois: The Library of Living Philosophers, pp: 278-292. Reprinted in Ideas and Opinions, 18-24, New York: Crown Publishers Incorp.

39. Beller M (2000) Kant's Impact on Einstein's Thought. In: Don Howard and John Stachel (Ed.), Einstein: The Formative Years, Boston: Birkhauser, pp: 1879-1909, 83106.

40. Howard D (1994) Einstein, Kant and the Origins of Logical Positivism. In: H. Reichenbach (Ed.), Language, Logic and the Structure of Scientific Theories: The Carnap-. Wesley Salmon and Gedeon Wolters, Pittsburgh: University of Pittsburgh Press, pp: 45-105.

41. Einstein A (1954) Relativity and the Problem of Space. In: Ideas and Opinions, New York: Crown Publishing Inc, pp: 360-370.

42. Kant I (1787/1998) The Critique of Pure Reason. Paul Guyer, Allen W. Wood (Transl). Wood. Cambridge: Cambridge University Press.

43. Duhem Pierre $(1906,1954)$ The Aim and Structure of Physical Theory.Princeton, New Jersey: Princeton University Press.

44. Quine WV (2000) Two Dogmas of Empiricism. In: Klemke ED (Ed.), Contemporary Analytic and Linguistic Philosophy. NY: Prometheus Books, pp: 331-349.

45. Einstein A (1918) Motive des Forschens, In: Zu Max Planks Sechszigstem Geburtstag. Ansprachen, gehalten am 26 April 1918 in der Deutschen Physikalischen Gesellchaft, Karlsruhe: Muller, pp: 29-32.

46. Einstein A (1902) Über die thermodynamische Theorie der Potentialdifferenz zwischen Metallen und vollständig dissozierten Lösungen ihrer Salze, und eine elektrische Methode zur Erforschung der Molekularkräfte. Ann Phys 8: 798-814. English translation by Anna Beck In: The Collected papers of Albert Einstein (1989) The Swiss years: writings, 1900 - 1909. Princeton, New Jersey: Princeton University Press, 2: 12-29.

47. Einstein A (1903) Eine Theorie der Grundlagen der 


\section{Philosophy International Journal}

Thermodynamik. Ann Phys 11: 170-187. English translation by Anna Beck In: The Collected Papers of Albert Einstein (1989) The Swiss years: writings, 1900 1909. Princeton, New Jersey: Princeton University Press, 2: 48-67.

48. Einstein A (1904) Zur allgemeinen molekularen Theorie der Warme. Ann Phys 14: 354-362. English translation by Anna Beck In: The Collected Papers of Albert Einstein (1989) The Swiss years: writings, 1900 - 1909. Princeton, New Jersey: Princeton University Press, 2: 68-77.

49. Miller A (1981) Albert Einstein's Special Theory of Relativity. London: Addison-Wesley.

50. Stachel J (2000) Introduction to Einstein: The Formative Years, In: Howard D, Stachel J (Eds.), Einstein. The Formative Years, Boston: Birkhauser, pp: 1-21.

51. Einstein Albert (1936/1954) Physics and Reality, The Journal of the Franklin Institute 221(3), March 1936. Reprinted in: Ideas and Opinions, 297-332, New York: Crown Publishing Inc.

52. Einstein A (1910) Principé de relativité et ses consequencé dans la physique modern. Archives des Sciences Physique et Naturelles 29: 125-144.

53. Norton J D (2010) How Hume and Mach Helped Einstein Find Special Relativity, In: Dickson M, Domski M (Eds.), Discourse on a New Method. Reinvigorating the Marriage of History and Philosophy of Science, Chicago and La Salle, IL: Open Court, pp: 359-386.

54. Hentschel Klaus (2018) Photons: the History and Mental Models of Light Quanta. Springer.

55. Pais A (1979) Einstein and the Quantum Theory. Rev Mod Phys 51: 863-914.

56. Einstein A (1905e) Ist die Trägheit eines Körpers von seinem Energienhalt abhängig? Ann Phys 18: 639641. English translation of Anna Beck In: The Collected Papers of Albert Einstein (1989) The Swiss years: writings, 1900 - 1909. Princeton, New Jersey: Princeton University Press, 2: 172-174.

57. Einstein A (1989) The Collected papers of Albert Einstein. The Swiss years: writings. Princeton, New Jersey: Princeton University Press, 2: 1900-1909.
58. Einstein A (1909) Über die Entwicklung unserer Anschauungen über das Wesen und die Konstitution der Strahlung. Physikalische Zeitschrift 10: 817-825. English translation of Anna Beck In: The Collected Papers of Albert Einstein (1989) The Swiss years: writings, 1900 1909. Princeton, New Jersey: Princeton University Press, 2: 379-394.

59. Einstein A (1907) Über das Relativitätsprinzip und die aus demselben gezogenen Folgerungen. Jahrbuch der Radioaktivität und Elektronik: 4: 411-462. English translation of Anna Beck in: The Collected Papers of Albert Einstein (1989) The Swiss years: writings, 1900 1909. Princeton, New Jersey: Princeton University Press, 2: 252-311.

60. Nugayev, Rinat (1999) Reconstruction of Mature Theory Change: A Theory-Change Model. Frankfurt am Main: Peter Lang.

61. Einstein A (1905b) Eine neue Bestimmung der Moleküldimensionen. University of Zurich Dissertation. English translation by Anna Beck In: The Collected Papers of Albert Einstein (1989) The Swiss years: writings, 1900 - 1909. Princeton, New Jersey: Princeton University Press, 2: 104-122.

62. Einstein A (1949b) Remarks Concerning the Essays Brought together in this Co-operative Volume. In: Albert Einstein: Philosopher-Scientist, Schlipp PA (Ed), Evanston, IL, 1-2: 665-688.

63. Lenzen VF (1949) Einstein's Theory of Knowledge. In: Schlipp PA (Ed.), Albert Einstein: Philosopher-Scientist, Evanston, IL, 1-2: 357-384.

64. Don Howard (2014) Einstein and the Development of Twentieth-Century Philosophy of Science. In: Michel J, Cristoph L (Eds.), Cambridge Company to Einstein. Cambridge: Cambridge University Press, pp: 354-376.

65. Ryckman T (2005) The Reign of Relativity: Philosophy in Physics. Oxford: Oxford University Press.

66. Kant I (1783/2002) Prolegomena to any future metaphysics that will be able to come forward as science. Repr. Transl. by Gary Hatfield. In: Immanuel Kant. Theoretical Philosophy after 1781. Cambridge: Cambridge University Press. 